\title{
Electronic Structure and Magnetic Properties of $\mathrm{N} @ \mathrm{C}_{60}-\mathrm{SWCNT}$
}

\author{
Atsushi Suzuki and Takeo Oku \\ The University of Shiga Prefecture \\ Japan
}

\section{Introduction}

Single-walled-carbon nanotube (SWCNTs) encapsulating fullerenes as peapods have been considerably interested to apply organic field effect transistor, magnetic device and quantum device (Bailey et. al. 2007, Khlobystrov et. al. 2005). Electronic structure and physical properties of fullerenes within SWCNT as carbon peapods has been studied. Table 1 lists recent works. For instant, the endohedral metallofullerenes nested in the strained nanotube have the electronic structure with the relative energy levels at the different states and produces a spatial modulation of the energy gap (Cho et. al. 2003). A scalable spin quantum computer that combines aspects of electronic and magnetic properties of endohedral fullerenes that enclose small clusters of metal atoms, such as $\mathrm{Sc}_{2} @ \mathrm{C}_{84}$, La@ $\mathrm{C}_{82}$ (as shown in Fig. 1) and Gd@ $\mathrm{C}_{82}, \mathrm{~N} @ \mathrm{C}_{60}$ and $\mathrm{P} @ \mathrm{C}_{60}$ encapsulated within SWCNT as peapods has been investigated (Tooth et. al. 2008, Cantone et. al. 2008, Warner et. al. 2008, Cho et. al. 2003, Yang et. al. 2010). The key advantages are that magnetic interactions between electronic spins and nuclear spins in carbon peapods are used. As an example using nitrogen endohedral fullerene $\mathrm{N} \mathrm{C}_{60}$ encapsulated within SWCNT as peapods (see Fig. 2), the nitrogen atom occupies a high-symmetry site at the center of the cage and retains its atomic configuration, and the cage offers protection of the nitrogen electron paramagnetic moment, which is related to electron spins, $S=3 / 2$, coupled to be nuclear spin $I=1$. This material has a high advantage of the NMR quantum computer to control spin gate with decoupling pulses in relaxation time. Morton reported the NMR quantum-computer controlled un-perturbation Rabi oscillation of spin polarization under influence of decoupling process (Morton, et. al. 2005, 2006, 2011). Additionally, nitrogen endohedral fullerene ${ }^{14} \mathrm{~N} @ \mathrm{C}_{60}$ encapsulated within SWCNT allow to control quantum qubit-gate under a mixture of biding interaction between electron and nuclear spins in the NMR quantum computing. Recently, Yang reported how to efficiently implement the quantum logical gate operations required for universal quantum computation. Transfer of information between qubits had been considered by direct dipole-dipole couplings or by using a mobile electron spin as the bus qubit (Yang et. al. (2010), Meyer et. al. (2004)).

The band structures for infinite periodic chains of $\mathrm{C}_{60}$ and $\mathrm{N} @ \mathrm{C}_{60}$ are shown in Fig. 2. All the energies are given in units of $\mathrm{E}-\mathrm{E}_{\mathrm{F}}$ for each system. The effects of encapsulated nitrogen on the band structure of $\mathrm{C}_{60}$ have been considered. The results reveal that the nitrogen causes the lowering of the $\mathrm{C}_{60}$ at the LUMO and HOMO levels together with a splitting of the degenerate levels. 


\begin{tabular}{|c|c|}
\hline Contents & References \\
\hline \multirow[t]{2}{*}{ Fullerene-based quantum computer } & $\begin{array}{l}\text { Morton et. al. (2005), (2006), (2011), Yang et. } \\
\text { al. (2010) }\end{array}$ \\
\hline & $\begin{array}{l}\text { Harneit et. al. (2002), Meyer et. al. (2004), } \\
\text { Benjamin et. al. (2006) }\end{array}$ \\
\hline \multirow[t]{2}{*}{ N@C $60-S W C N T, P @ C_{60}-S W C N T$} & $\begin{array}{l}\text { Cho et. al. (2003), Bailey et. al. (2007), Jue et. } \\
\text { al. (2007), }\end{array}$ \\
\hline & $\begin{array}{l}\text { Simon et. al. (2006) (2007), Tooth et. al,. (2008), } \\
\text { Yang et. al. (2010), Suzuki et. al. (2010), Iizumi } \\
\text { et. al. (2010) }\end{array}$ \\
\hline Sc@C $82-S W C N T, L a @ C_{82}-S W C N T$ & $\begin{array}{l}\text { Cho et. al. (2003), Cantone et. al. (2008), } \\
\text { Warner et. al. (2008) }\end{array}$ \\
\hline Carbon tubes & Rao et. al. (1997), Khlobystrov et. al. (2005) \\
\hline $\mathrm{C}_{60}$ & Schiller et. al. (2006) \\
\hline \multirow[t]{3}{*}{$\mathrm{N} @ \mathrm{C}_{60}, \mathrm{P} @ \mathrm{C}_{60},\left(\mathrm{C}_{59} \mathrm{~N}\right)_{2,}, \mathrm{C}_{59} \mathrm{~N}$} & Buhl et. al. (1997), Fulop et. al. (2001), \\
\hline & Kobayashi et. al. (2003), \\
\hline & Abronin et. al. (2004), Schulte et. al. (2007) \\
\hline
\end{tabular}

Table 1. Electronic structure and physical properties of fullerenes within SWCNT as carbon peapods

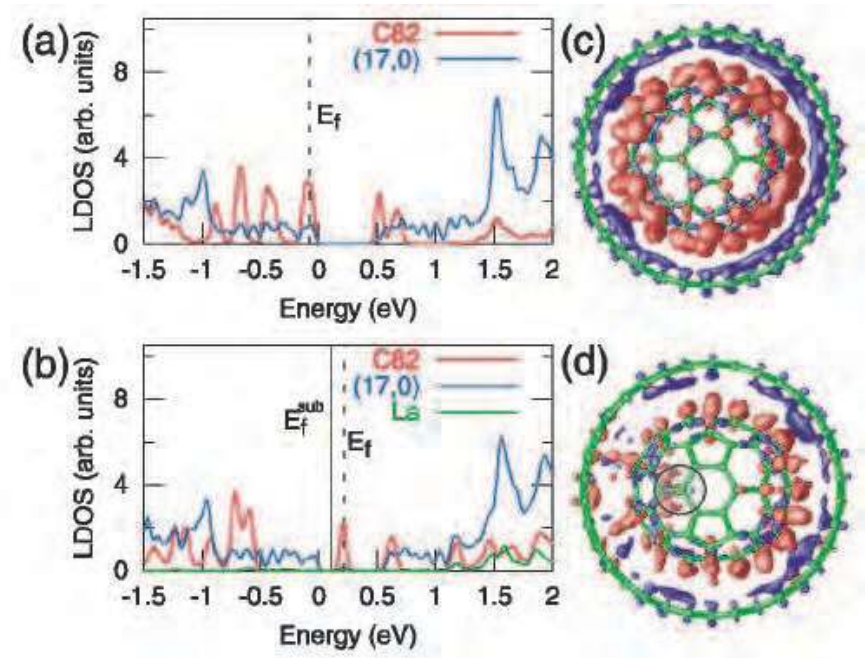

Fig. 1. Local density of states (LDOS) of (a) $\mathrm{C}_{82} @(17,0)$ and (b) La@ $\mathrm{C}_{82} @(17,0)$ decomposed into the constituents. Black vertical lines indicate the Fermi level $(E f)$. $E_{\text {sub }} f$ represents the Fermi level with the metal substrate in contact. Isodensity surface plots of the electron accumulation (red) and depletion (blue) are shown for $\mathrm{C}_{82}$-SWCNT $(17,0)$ and La@C $82-$ $\operatorname{SWCNT}(17,0)$ in $(\mathrm{c})$ and $(\mathrm{d})$, respectively. The values for the red and blue surfaces in (c) are $\pm 0: 0035 \mathrm{e} / \mathrm{e}^{3}$. Corresponding values in $(\mathrm{d})$ are $\pm 0: 0025 \mathrm{e} / \mathrm{e}^{3}$. The gray circle in $(\mathrm{d})$ indicates the position of the La atom inside $\mathrm{C}_{82}$. (Cho et. al. (2003))

The gap between HOMO and LUMO is reduced from 1:8 eV of $\mathrm{C}_{60}$ to 1:66 eV of $\mathrm{N} @ \mathrm{C}_{60}$. The effects of majority and minority spins in the nitrogen basis were found not to have any 
appreciable further contribution. These small changes to the band gap and Fermi level shifts the support to the evidence that the nitrogen atom is well screened within the cage.
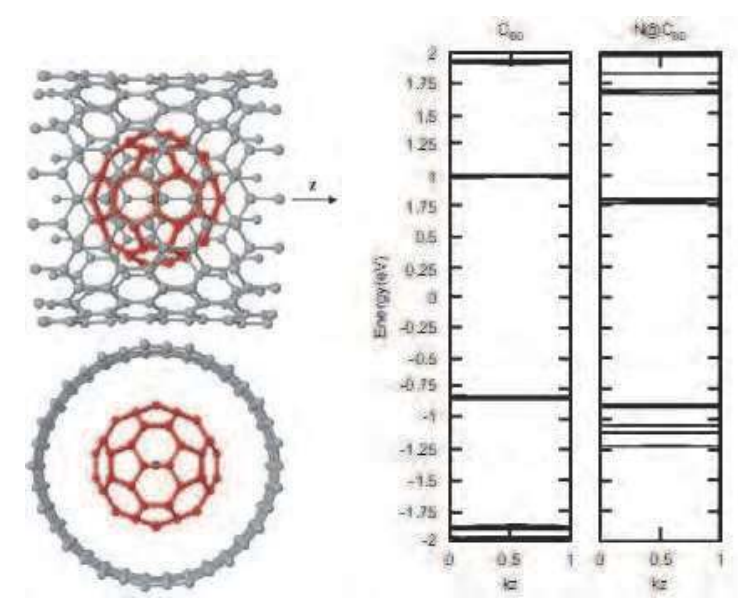

Fig. 2. The relaxed atomic coordinates of $\mathrm{N} @ \mathrm{C}_{60}-\mathrm{SWCNT}(17,0)$. For clarity the carbon atoms of the $\mathrm{C}_{60}$ are shown in red and the nitrogen in blue. The band structures for infinite periodic chains of $\mathrm{C}_{60}$ and $\mathrm{N} @ \mathrm{C}_{60}$ are shown. All the energies are given in units of $\mathrm{E}-\mathrm{E}_{\mathrm{F}}$ for each system. (Bailey et. al. (2007))

Design of spin labels inside for possible molecular spintronics, which contains of 1D spin chains filling SWCNTs with magnetic endohedral fullerenes of $N @ C_{60}$ and $P_{0} @ C_{60}$ as spin qubit have been proposed (Yang et. al. 2010). Jue reported a scheme to implement the twoqubit gates between the nuclear spins of the encapsulated atoms in endohedral fullerenes ${ }^{15} \mathrm{~N} @ \mathrm{C}_{60}$ or ${ }^{31} \mathrm{P} @ \mathrm{C}_{60}$, within today's magnetic resonance techniques (Jue et. al. 2007). The electronic spin of the $\mathrm{N}$ and $\mathrm{P}$ ground state is $3 / 2$, while the nuclear spin is either $1 / 2(15 \mathrm{~N}$, $\left.{ }^{31} \mathrm{P}\right)$ or $1\left({ }^{14} \mathrm{~N}\right)$. The electronic structure at highest occupied molecular orbital (HOMO), lowest unoccupied molecular orbital (LUMO), the magnetic and optical properties of $\mathrm{N} @ \mathrm{C}_{60}-\mathrm{SWCNT}$ have been characterized on the basis of magnetic techniques of NMR, ESR and electronic nuclear double resonance (ENDOR) (Benjamin, et. al. 2006) using ab-nitio quantum calculation. The relaxation properties of the ${ }^{14} \mathrm{~N}$ nucleus in $\mathrm{N} @ \mathrm{C}_{60}$ were determined using techniques related to Davies ENDOR which have been proposed for measuring $T_{1}$ and $T_{2}$. In order to demonstrate the effectiveness of the bang-bang decoupling scheme in $\mathrm{N} @ \mathrm{C}_{60}$, a strong environmental interaction has been simulated by applying a strong RF field to drive Rabi oscillations in the nuclear spin; this strong RF field was then decoupled by applying fast phase 'kicks' using the $\Pi$ phase gate (Morton et. al. (2006)).

Figure 3 shows Bang-bang control of fullerene qubits by ultrafast phase gates. Morton discussed the benefits of a coupled electron spin to the nuclear spin qubit and demonstrated the ideas using the ${ }^{14} \mathrm{~N}$ nuclear spin in the $\mathrm{N} @ \mathrm{C}_{60}$ molecule. In addition to providing a resource for nuclear spin polarization and detection, the electron spin can be exploited to perform ultrafast nuclear spin phase gates, which can in turn be used to dynamically bangbang decouple the nuclear spin from unwanted interactions. Figure 4 shows arbitrary nuclear phase gates are implemented by driving two electron spin transitions simultaneously (Morton (2005)). The path of the electron magnetization vector was driven 
by a microwave field. The corresponding z-magnetizations are displayed as shown in Fig. 4 (a). One transition is driven resonantly, and one strongly detuned. On each cycle, the phase accumulated is proportional to the area enclosed by the path. Both transitions must undergo an integer number of complete cycles to ensure the populations remain unchanged. As shown in Fig. 4 (b), both transitions were detuned by equal and opposite amounts, the population evolution for each is the same, whilst the phase accumulated is of opposite sign. Hence, the relative phase shift can be tuned by controlling the microwave pulse power.

The effect of the non-nearest neighbor couplings has been investigated (Yang et. al. (2010)). Figure 5 show transitions of a single qubit in the presence of couplings to other qubit as a function of the chain length. The uppermost spectrum corresponds to the case of nearest neighbors only [trace (a)]. If non-nearest neighbors are added [see trace (b)], each resonance line splits into seven lines separated by $D_{\mathrm{nn}} / 8$, where $D_{\mathrm{nn}}$ is the coupling between nearest neighbors. The weight of the lines (1:2:3:4:3:2:1) is given by the number of states of the nextnearest neighbors. Adding a third pair of qubits causes an additional splitting of each line into a (1:2:3:4:3:2:1) multiplet, with line separation $D_{\mathrm{nn}} / 64$. With the resolution of the figure [see trace (c)], this appears as a line broadening. The ESR frequency on transitions of a single qubit was appeared in the presence of couplings to other qubit under nearest neighbor. Especially, electronic spin qubits on five molecules of $\mathrm{N} @ \mathrm{C}_{60}$ in a magnetic field gradient has been simulated. The magnetic parameters of principle g-tensor, hyperfine coupling constant of nitrogen atom and chemical shift of ${ }^{13} \mathrm{C}$ in ${ }^{14} \mathrm{~N} @ \mathrm{C}_{60}$ within SWCNT for chiral index $(\mathrm{n}, \mathrm{m})$ are important to control a quantum qubit-gate of $1 \mathrm{D}$ spin in the NMR quantum-computer. In the present work, geometrical effect of diameter and chiral index on the electronic structure, magnetic and optical properties of $\mathrm{N} @ \mathrm{C}_{60}-\mathrm{SWCNT}$ have been investigated on the basis of experimental results using ab-initio density functional theory.

(a)

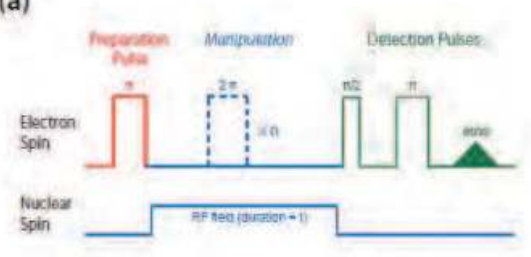

(b)

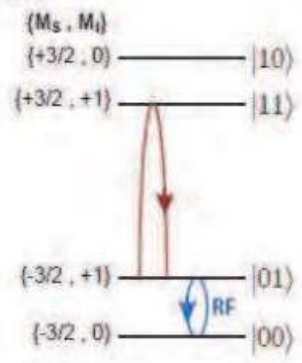

(c)

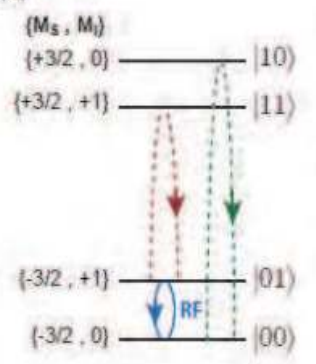

(b)

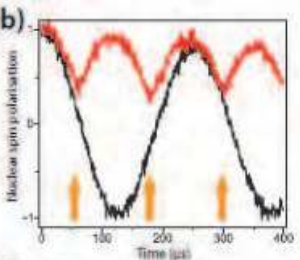

(c)
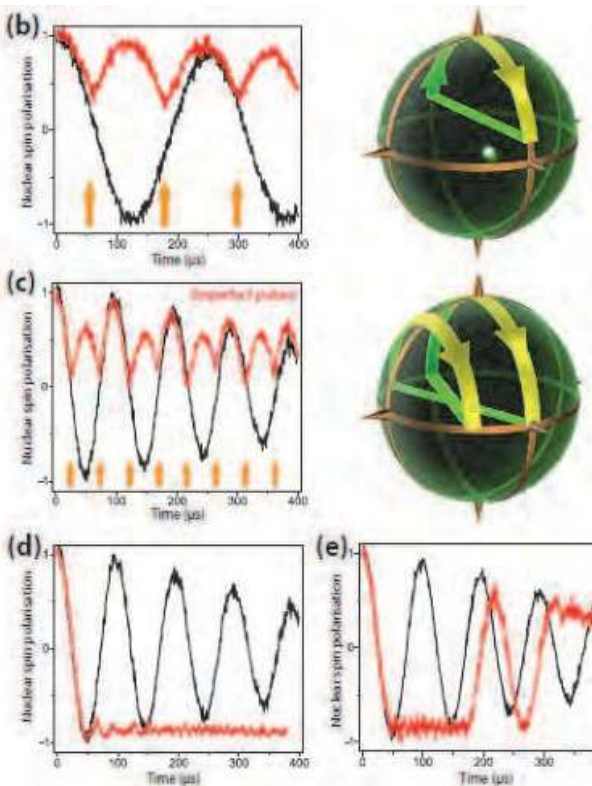
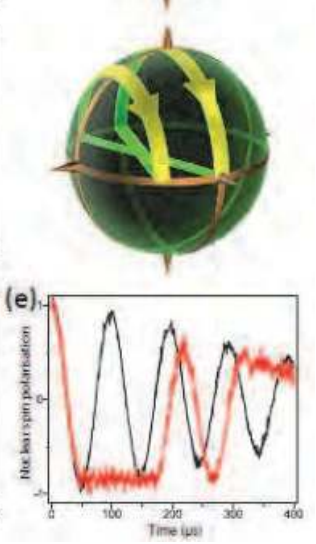

Fig. 3. Bang-bang control of fullerene qubits by ultrafast phase gates. (Morton et. al. (2006)) 

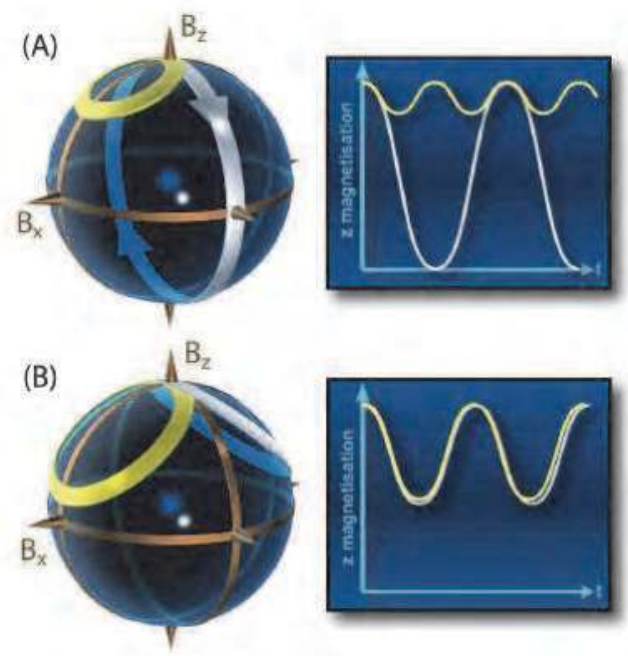

Fig. 4. Arbitrary nuclear phase gates are implemented by driving two electron spin transitions simultaneously (Morton (2005))

(a)

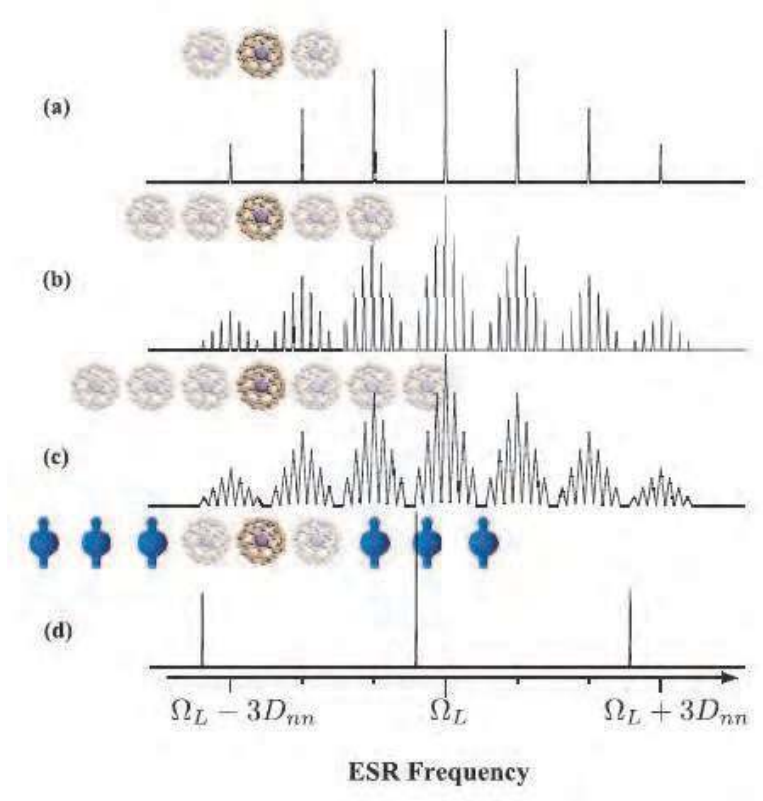

Fig. 5. Transitions of a single qubit in the presence of couplings to other qubits as a function of the chain length. (a) Nearest neighbors only. (b) Nearest neighbors and next-nearest neighbors. (c) Three qubits on each side. (d) Infinite chain, where all but the nearest neighbors are polarized. (Yang et. al. (2010)) 


\section{Quantum chemical calculation}

The molecular structures were assembled by CS ChemDraw, CS Chem3D (Cambridge Soft) and Nanotube Modeler (JCrystal Soft). Molecular orbital calculations were carried out by molecular mechanics calculations (MM2) and semi-empirical molecular orbital calculations (Hamiltonian: Parameterized Model Revision 3: PM3). In addition, the isolated molecular structures were optimized by ab-initio quantum calculation using unrestricted Hartree-Fock (UHF) and DFT using UB3LYP with hybrid function LANL2DZ and STO-3G*, 3-31G* and 6$31 \mathrm{G}^{*}$ as basis set (Gaussian 03 Inc.). The electronic structure at HOMO, LUMO, LUMO+1 and the HOMO-LUMO band gap $\left(E_{g}\right)$ were calculated. Nitrogen atomic charges of ${ }^{14} \mathrm{~N} @ \mathrm{C}_{60}$ within SWCNT were estimated using Mulliken population analysis. Wavelength and the exited transition state were calculated by time-dependence of DFT (TD-DFT) with hybrid function UB3LYP and 3-31G* as basis set. Continuously, chemical shift of ${ }^{13} \mathrm{C}(\delta)$, principle g-tensor $\left(g_{x x}, g_{y y}, g_{z z}\right)$ and principle A-tensor $\left(A_{x x}, A_{y y}, A_{z z}\right)$ in hyperfine coupling constant (hfc) of nitrogen atom were calculated by DFT using NMR/GIAO with hybrid function UB3LYP and $3-31 G^{*}$ as basis set.

\section{Results and discussion}

\subsection{Electronic structure of $\mathrm{N} @ \mathrm{C}_{60}-\mathrm{SWCNT}$}

Electronic structure of molecular orbital at HOMO, LUMO, next LUMO+1 and energy levels of N@C $\mathrm{C}_{60}$-SWCNT-armchair have been investigated by DFT with hybrid function UB3LYP using 6-31G* as basis set. Molecular orbitals and energy levels of ${ }^{14} \mathrm{~N} @ \mathrm{C}_{60}-\mathrm{SWCNT}$ armchair $(13,13), \mathrm{N} @ \mathrm{C}_{60}$ and SWCNT are shown in Fig. 6. The molecular orbital of N@C $60-\mathrm{SWCNT}$ zigzag $(13,13)$ was delocalized on $\pi$-electrons at a long axis of SWCNT surface interacted with $\pi$-electrons on the $\mathrm{N} @ \mathrm{C}_{60}$ cage surface as hybrid orbital interaction. The energy level between HOMO-LUMO was smaller than that of original SWCNT. This behavior was due to a mixture of binding interaction with spin distribution.

Molecular orbital of ${ }^{14} \mathrm{~N} @ \mathrm{C}_{60}-\mathrm{SWCNT}(9,9)$ and SWCNT at (a) HOMO, (b) LUMO, (c) LUMO+1 are shown in Fig. 7. The molecular orbital of $\mathrm{N} @ \mathrm{C}_{60}-\mathrm{SWCNT}$-zigzag $(9,9)$ was delocalized on $\pi$-electrons at a long axis of SWCNT surface interacted with $\pi$-electrons on the $\mathrm{N} @ \mathrm{C}_{60}$ cage surface as hybrid orbital interaction. The energy gap of $\mathrm{N} @ \mathrm{C}_{60}-\mathrm{SWCNT}$ between HOMO and LUMO was estimated to be $1.16 \mathrm{eV}$, which was smaller than that of original SWCNT $(9,9)$ to be $1.24 \mathrm{eV}$, due to a mixture of binding interaction. Mulliken atomic charge of $\mathrm{N}$ in ${ }^{14} \mathrm{~N} @ \mathrm{C}_{60}$ within $\mathrm{SWCNT}$ was $3.8 \times 10^{-5} \mathrm{e}$. This result indicates a slight charge transfer from nitrogen atom to $\mathrm{C}_{60}$ cage within SWCNT. This supports the assertion that the nitrogen is well screened within the $\mathrm{C}_{60}$ cage.

Electronic structures of $\mathrm{N} @ \mathrm{C}_{60}-\mathrm{SWCNT}$-zigzag $(14,0)$ at (a) HOMO, (b) LUMO and (c) charge distribution are shown in Fig. 8. The molecular orbital were well distributed around the SWCNT interacted with $\mathrm{C}_{60}$ surface cage. Energy gap between HOMO and LUMO was estimated to be $0.87 \mathrm{eV}$, which indicates semi-conductive behavior. There existed a wide charge distribution on the inner surface of SWCNT, which had $\pi$-electron interaction with hybrid orbital on the $\mathrm{C}_{60}$ surface cage.

Figure 9 show molecular orbital of $\left({ }^{14} \mathrm{~N} @ \mathrm{C}_{60}\right)_{2}$-SWCNT-armchair $(9,9)$ at (a) HOMO and (b) LUMO, calculated by DFT/UB3LYP/STO-3G*. In both cases at HOMO and LUMO, molecular orbital of $\left({ }^{14} \mathrm{~N} @ \mathrm{C}_{60}\right)_{2}$-SWCNT $(9,9)$ formed a circle ring to distribute on the SWCNT surface. The band gap between HOMO and LUMO was estimated to be $3.72 \mathrm{eV}$, 
(a) HOMO

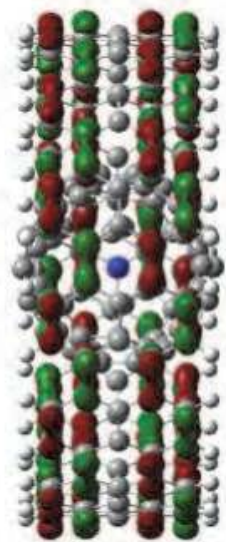

$-2.02 \mathrm{eV}$ (b) LUMO

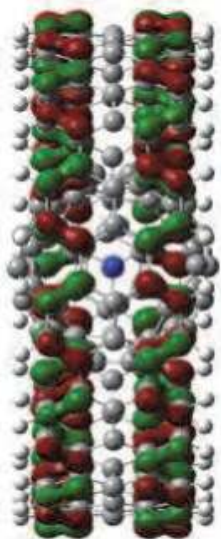

$-1.25 \mathrm{eV}$

$$
E g=0.76 \mathrm{eV}
$$

(c) LUMO+1

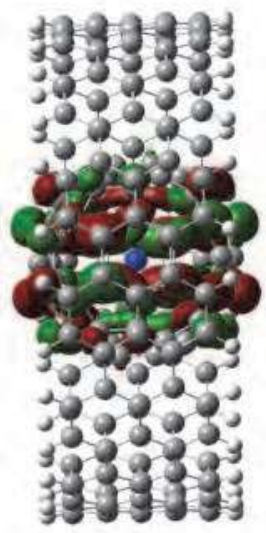

$-0.71 \mathrm{eV}$
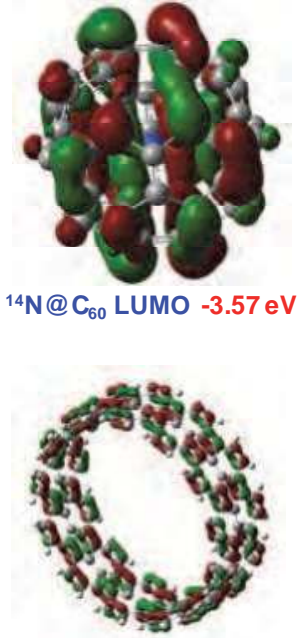

SWCNT $(13,13)$ HOMO $-4.06 \mathrm{eV}$

$E g=1.20 \mathrm{eV}$

Fig. 6. Molecular orbitals and energy levels of ${ }^{14} \mathrm{~N} @ \mathrm{C}_{60}-\mathrm{SWCNT}$ armchair $(13,13), \mathrm{N}_{\mathrm{C}} \mathrm{C}_{60}$ and SWCNT (Suzuki, el. al. (2010))

$\mathrm{N} @ \mathrm{C}_{60}-\mathrm{SWCNT}(9,9)$
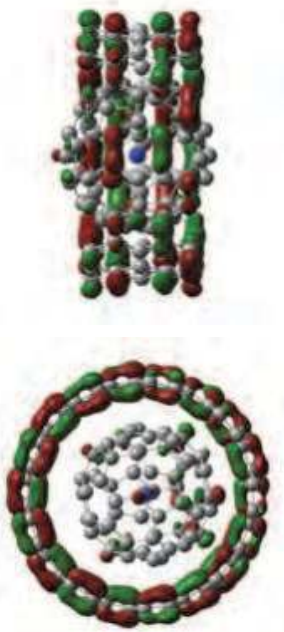

(a) HOMO $-4.05 \mathrm{eV}$
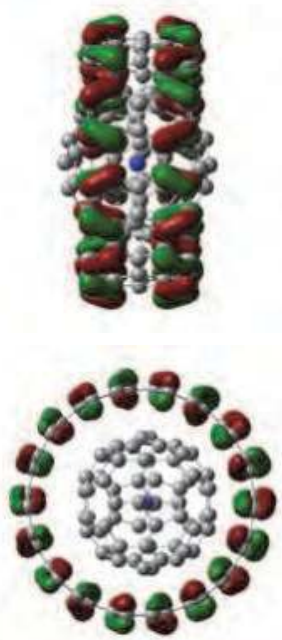

(b) LUMO $-2.89 \mathrm{eV}$
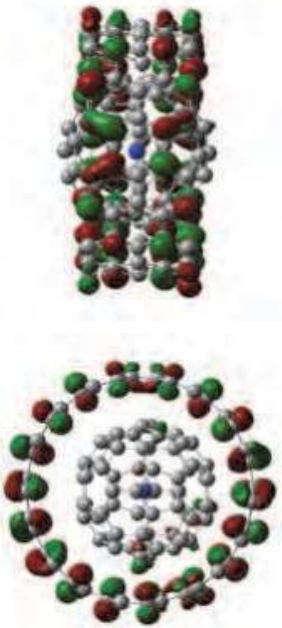

(c) LUMO+1 $-2.26 \mathrm{eV}$
SWCNT $(9,9)$

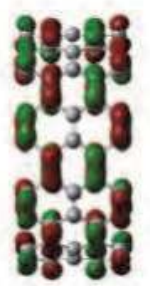

(a) HOMO $-4.08 \mathrm{eV}$

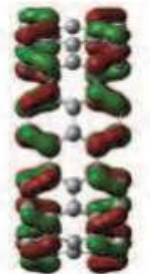

(b) LUMO $-2.84 \mathrm{eV}$

Mulliken $\mathrm{N}$ atomic charge

0.000038

Fig. 7. Molecular orbital of ${ }^{14} \mathrm{~N} @ \mathrm{C}_{60}-\operatorname{SWCNT}(9,9)$ and SWCNT at (a) HOMO, (b) LUMO, (c) LUMO+1 and energy levels (Suzuki et. al. (2010)). 

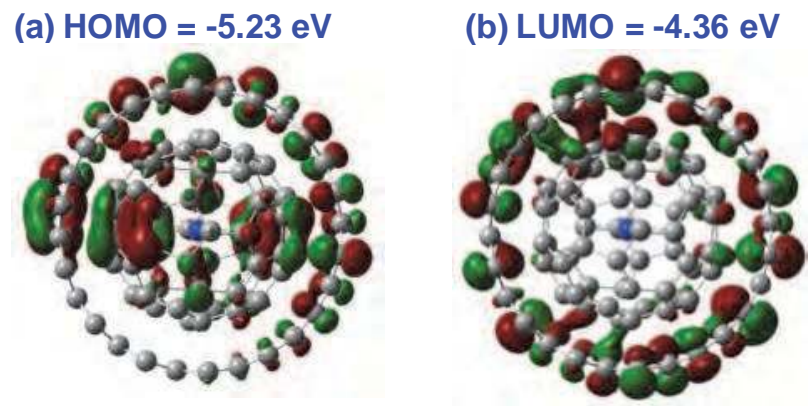

(c) Charge distribution

Fig. 8. Molecular orbital of ${ }^{14} \mathrm{~N} @ \mathrm{C}_{60}-\mathrm{SWCNT}$-zigzag $(14,0)$ at (a) HOMO, (b) LUMO and (c) charge distribution. (Suzuki et. al. (2010))

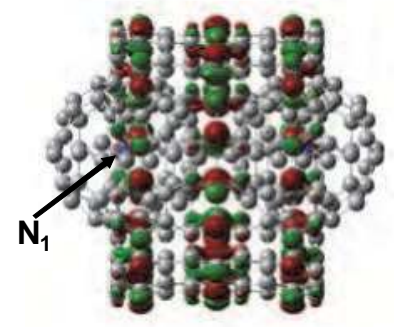

(a) HOMO

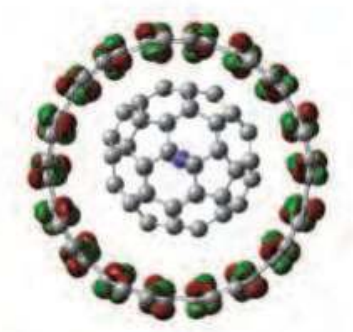

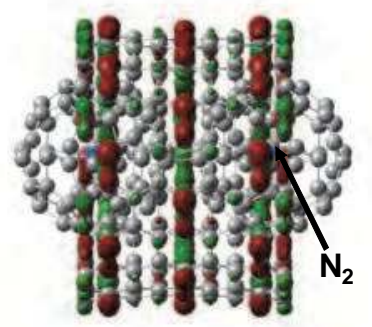

(b) LUMO

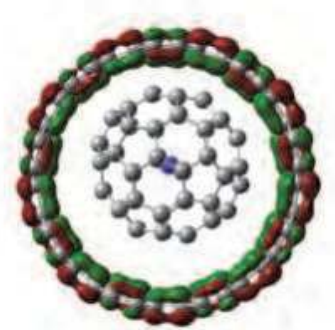

LUMO+1 $=2.21 \mathrm{eV}$

LUMO $=0.71 \mathrm{eV}$

HOMO $=-3.01 \mathrm{eV}$

HOMO-1 $=-4.39 \mathrm{eV}$

$E_{g}=3.72 \mathrm{eV}$

Mulliken atomic charge / N

$\mathrm{N}_{1}=2.998, \mathrm{~N}_{2}=2.998$

Fig. 9. Electronic structures of $\left({ }^{14} \mathrm{~N} @ \mathrm{C}_{60}\right)_{2}-\mathrm{SWCNT}-\operatorname{armchair}(9,9)$ at (a) HOMO and (b) LUMO. (Suzuki et. al. (2010))

which was larger than $1.72 \mathrm{eV}, 3.06 \mathrm{eV}$ and $2.11 \mathrm{eV}$ of $\operatorname{SWCNT}(9,9), \mathrm{N} @ \mathrm{C}_{60}$ and $\left(\mathrm{N} @ \mathrm{C}_{60}\right)_{2}$. Mulliken atomic charge of nitrogen atom in $\left({ }^{14} \mathrm{~N} @ \mathrm{C}_{60}\right)_{2}-\mathrm{SWCNT}(9,9)$ was estimated to be 2.998e. This positive charge indicates a considerable charge transfer from nitrogen atom to $\mathrm{C}_{60}$ cage within SWCNT.

\subsection{Electronic structure of $\mathbf{N} @ \mathrm{C}_{60}$}

Electronic structure of $\mathrm{N} @ \mathrm{C}_{60}(\mathrm{~S}=3 / 2, \mathrm{I}=1)$ at $\mathrm{HOMO}, \mathrm{LUMO}$ and energy levels are shown in Fig. 10. The molecular orbital was considerably distributed on the $\mathrm{C}_{60}$ surface cage. Mulliken $\mathrm{N}$ atom charge was $0.21 \mathrm{e}$, which indicates charge transfer from nitrogen atomic to the $\mathrm{C}_{60}$ 
surface cage. The energy gap between HOMO and LUMO was estimated to be $3.0 \mathrm{eV}$, which made agreement with the experimental energy gap of $\mathrm{N} @ \mathrm{C}_{60}(2.7 \mathrm{eV})$ adsorbed on $\mathrm{Cu}(887)$ surface. The molecular structure with the energy levels have been investigated by scanning tunneling microcopy/spectroscopy (STM/STS) and near-edge $x$-ray absorption fine structure (NEXAFS) spectrum (Schiller, et. al. 2006).

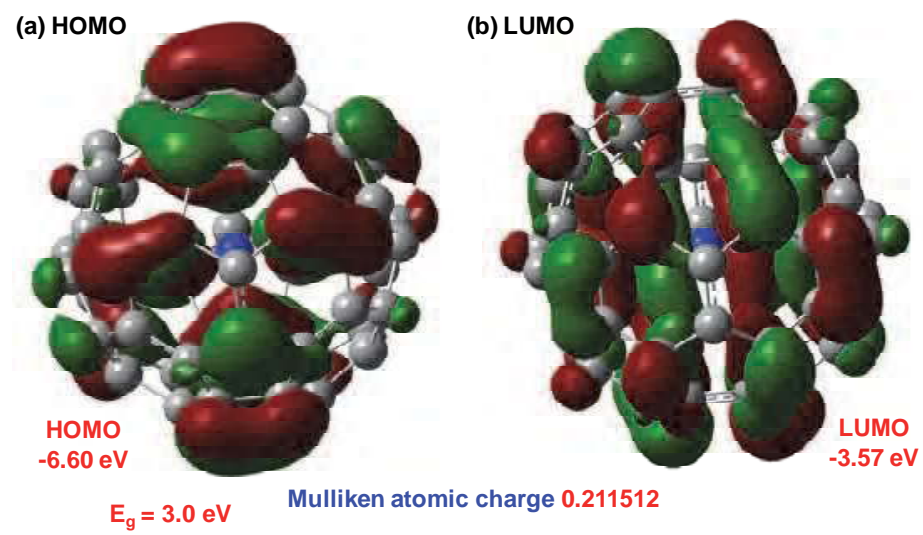

Fig. 10. Electronic structure and molecular orbital of $\mathrm{N} @ \mathrm{C}_{60}$ at (a) HOMO (a) and (b) LUMO (Suzuki et. al. (2010))

(a) HOMO $-5.95 \mathrm{eV}$

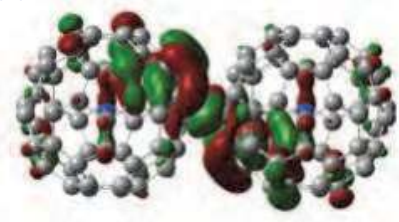

(b) HOMO-1 -6.12 eV

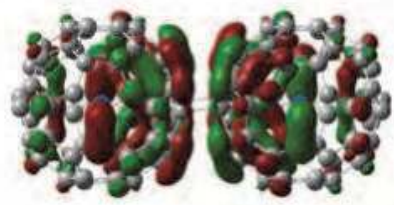

Band gap $\left(E_{g}\right)=2.11 \mathrm{eV}$ cf. $\mathbf{N} @ \mathbf{C}_{60} E g=3.0 \mathrm{eV}$

Mulliken atomic charge,

$\mathrm{N}_{1}$ and $\mathrm{N}_{2}=0.004299,0.004381$

cf. $\mathrm{N} @ \mathrm{C}_{60} \mathrm{~N}=-0.004522$ (c) LUMO+1 $-3.59 \mathrm{eV}$

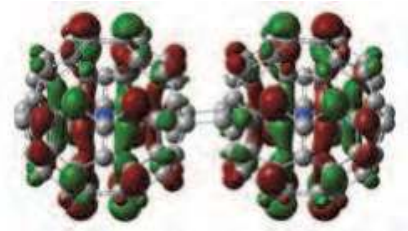

(d) LUMO $-3.84 \mathrm{eV}$

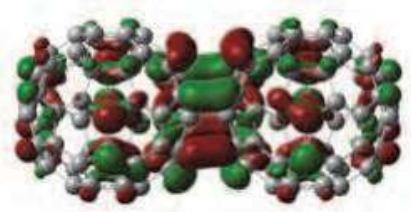

(e) Spin density

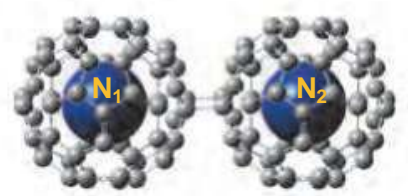

Fig. 11. Electronic structures of $\left(\mathrm{N} @ \mathrm{C}_{60}\right)_{2}$ at (a) HOMO, (b) HOMO-1, (c) LUMO+1, (d) LUMO and (e) spin density. (Suzuki et. al. (2010)) 
Electronic structures of $\left({ }^{14} \mathrm{~N} @ \mathrm{C}_{60}\right)_{2}$ as dimmer at (a) HOMO, (b) HOMO-1, (c) LUMO+1, (d) LUMO, (e) spin density and Mulliken atomic charge of $\mathrm{N}_{1}$ and $\mathrm{N}_{2}$ are shown in Fig. 11. The molecular orbital of the $\left(\mathrm{N} @ \mathrm{C}_{60}\right)_{2}$ at $\mathrm{HOMO}$ and $\mathrm{LUMO}$ were partial to distribute between the $\mathrm{C}_{60}$ surface cages. The molecular orbital was interacted with each other on $\Pi$ electron of hybrid orbital. The energy gaps between HOMO and LUMO were estimated to be $2.11 \mathrm{eV}$,

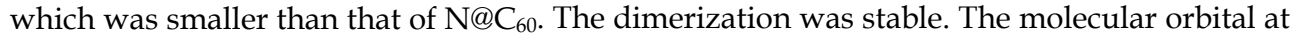
HOMO-1 and LUMO+1 were well distributed around the $\mathrm{C}_{60}$ cage surfaces. The molecular orbital was anti-interacted with each other, due to anti-bonding behavior of isolated molecular orbital of $\mathrm{N} @ \mathrm{C}_{60}$. Mulliken atomic charge of $\mathrm{N}_{1}$ and $\mathrm{N}_{2}$ in $\left(\mathrm{N} @ \mathrm{C}_{60}\right)_{2}$ were at 0.004299 e and 0.004381 e. The slight values of positive charge were due to slight charge transfer from $\mathrm{N}$ atoms to the surface cage of $\mathrm{C}_{60}$.

\subsection{Electronic structure of $\mathbf{C}_{60} \mathbf{N}$}

Electronic structure of $\mathrm{C}_{59} \mathrm{~N}(\mathrm{~S}=1 / 2, \mathrm{I}=1)$ at $\mathrm{HOMO}$ and LUMO are shown in Fig. 12. The molecular orbital were impartially distributed on the $\mathrm{C}_{60}$ cage surface. Mulliken $\mathrm{N}$ atomic charge was $-0.6 \mathrm{e}$. The negative value indicates considerable charge transfer from $\mathrm{C}_{60}$ cage to nitrogen atom. The energy gap between HOMO and LUMO was calculated to be $1.29 \mathrm{eV}$, which made agreement with the experimental result of $\left(\mathrm{C}_{59} \mathrm{~N}\right)_{2}$ at $1.1 \mathrm{eV}$ by C K NEXAFS spectrum (Schulte, et. al. 2007). The dimerization of $\left(\mathrm{C}_{59} \mathrm{~N}\right)_{2}$ was stable as compared with isolation of $\mathrm{C}_{59} \mathrm{~N}$.

(a) HOMO

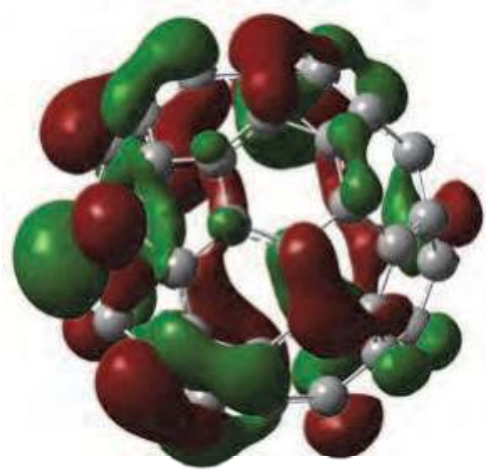

НОМО

$-4.58 \mathrm{eV}$

\section{(b) LUMO}

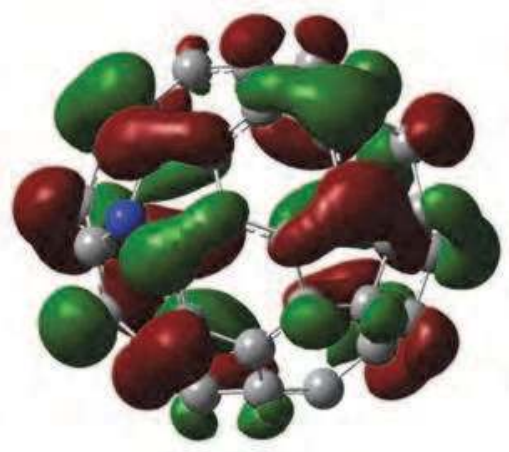

LUMO

$-3.29 \mathrm{eV}$

Fig. 12. Electronic structure and molecular orbital of $\mathrm{C}_{59} \mathrm{~N}$ at (a) HOMO and (b) LUMO.

(Suzuki et. al. (2010))

The single replacement in $\mathrm{C}_{59} \mathrm{~N}$ keeps the bond lengths close to the $\mathrm{C}_{60}$ values (1.40 and 1.45 $\AA)$. The dimerization has strong effects as shown in Fig. 13. The charge redistributes itself to weaken the intramolecular bonds of the tetra-coordinated ' $C^{\prime}$ and to strengthen both the N-C bonds on the pentagon and the "double" bonds in the hexagons containing $\mathrm{C}^{\prime}-\mathrm{N}$. This bond turns out to be a relatively weak one, as the electron density distribution emphasizes. In combination with the weak intermolecular $C^{\prime}-C^{\prime}$ bonding, this results in an electronic environment for $C^{\prime}$ remarkably different from that of a typical sp3 atom. This fact should 
account for the missing NMR signal in the sp3 region. Accurate calculations of the carbon chemical shifts would be highly desirable. Their calculations predict a very similar structure for the latter (anti-conformation), apart from the much elongated intermolecular distance (1.675 $\AA$ ). The anti-conformation has been determined also by less sophisticated calculations.

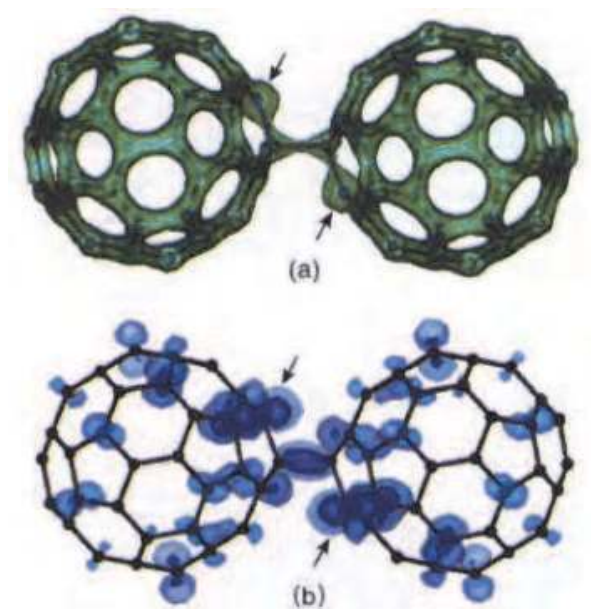

Fig. 13. For $\left(\mathrm{C}_{59} \mathrm{~N}\right)_{2}$ : Isodensity hypersurfaces of (a) the electron density and (b) the HOMO. Values (in au) are 0.2 (a); 0.002 (dark) and 0.0005 (light) (b). (Andreoni et. al. (1996))

\subsection{Electronic structure of $\left(\mathrm{C}_{60}\right)_{3}$ as trimmer}

Electronic structure of the $\mathrm{C}_{2 \mathrm{~h}}$ symmetry trimmer, $\left(\mathrm{C}_{60}\right)_{3}$ based on the $\mathrm{P} 4$ peanut has been studied (Beu 2006). The HOMO and LUMO energies obtained with the PBE (HCTH) functional are respectively $E_{\mathrm{HOMO}}=-0.175(-0.179)$ a.u. and $E_{\mathrm{LUMO}}=-0.171(-0.173)$ a.u. The distribution of the Mulliken charges in the two waist regions are similar to those of the dimmer (between -0.030 e and +0.056 e for the PBE functional). Figure 14 shows geometrical structure and HOMO-orbital (isovalue 0.01 ) of the $\mathrm{C}_{2 \mathrm{~h}}$ symmetry $\mathrm{C}_{60}$ trimer, $\left(\mathrm{C}_{60}\right)_{3}$ based on the P4 peanut. The HOMO-orbital qualitatively showed the same behavior, bridging the cages. A transverse nodal plane through the middle of the central cage seems to limit the delocalization of the electrons. Anyway, for all methods the HOMO-LUMO gap of the trimmer was significantly reduced as compared to the dimmer, $\left(\mathrm{C}_{60}\right)_{3}$, continuing the monotonous decrease with respect to the $\mathrm{C}_{60}$ monomer.

\subsection{Geometrical effect of $\mathrm{N} @ \mathrm{C}_{60}-\mathrm{SWCNT}, \mathrm{SWCNT}, \mathrm{N} @ \mathrm{C}_{60}$ and $\mathrm{C}_{59} \mathrm{~N}$ on electronic structure}

Geometrical effect of $\mathrm{N} @ \mathrm{C}_{60}-\mathrm{SWCNT}, \mathrm{SWCNT}, \mathrm{N} @ \mathrm{C}_{60}$ and $\mathrm{C}_{59} \mathrm{~N}$ on the electronic structure has been investigated by DFT using UB3LYP. Table 2 lists comparison between $\mathrm{N} \mathrm{C}_{60}-$ SWCNT, $\left(\mathrm{N} @ \mathrm{C}_{60}\right)_{2}-\mathrm{SWCNT}$, SWCNT, $\left(\mathrm{N} @ \mathrm{C}_{60}\right)_{2}, \mathrm{~N} @ \mathrm{C}_{60}$ and $\mathrm{C}_{59} \mathrm{~N}$ on energy levels at HOMO, LUMO and band gap $\left(\mathrm{E}_{\mathrm{g}}\right)$. The energy levels of $\mathrm{N} @ \mathrm{C}_{60}-\mathrm{SWCNT}$ were affected by diameter and chiral index. The energy levels of $\mathrm{N} @ \mathrm{C}_{60}-\mathrm{SWCNT}$ compared with SWCNT had effected with increasing diameters. Especially, the energy gap of $\mathrm{N} @ \mathrm{C}_{60}$-SWCNT was smaller than those of SWCNT, N@ $\mathrm{C}_{60}$ and $\mathrm{C}_{59} \mathrm{~N}$. This behavior would be originated in narrowing energy gap based on molecular interaction between $\mathrm{N} @ \mathrm{C}_{60}$ and SWCNT. These 
behaviors of ${ }^{14} \mathrm{~N} @ \mathrm{C}_{60}-\mathrm{SWCNT}$ were considerably closed to those in density of state (DOS), which calculated with a tight binding model for SWCNT armchair. Electronic density of states (DOS) calculated with a tight binding model for SWCNT armchair $(8,8),(9,9),(10,10)$, and $(11,11)$ are shown in Fig. 16. The HOMO-LUMO gaps of SWCNT $(n, n)$ for $n=9-13$ as metal were inverse proportion to the diameters (Rao, et al. 1997). The energy gap of $\left(\mathrm{N} @ \mathrm{C}_{60}\right)_{2-}$ SWCNT $(9,9)$ was extend to be $3.72 \mathrm{eV}$ as compared with that of $N @ \mathrm{C}_{60}-\mathrm{SWCNT}(9.9)$, due to instable dimmer within SWCNT. As reference, the energy gap of dimmer, $\left({ }^{14} \mathrm{~N} @ \mathrm{C}_{60}\right)_{2}$ was estimated to be $2.11 \mathrm{eV}$, which was smaller than that of ${ }^{14} \mathrm{~N} @ \mathrm{C}_{60}$, due the stable formation.

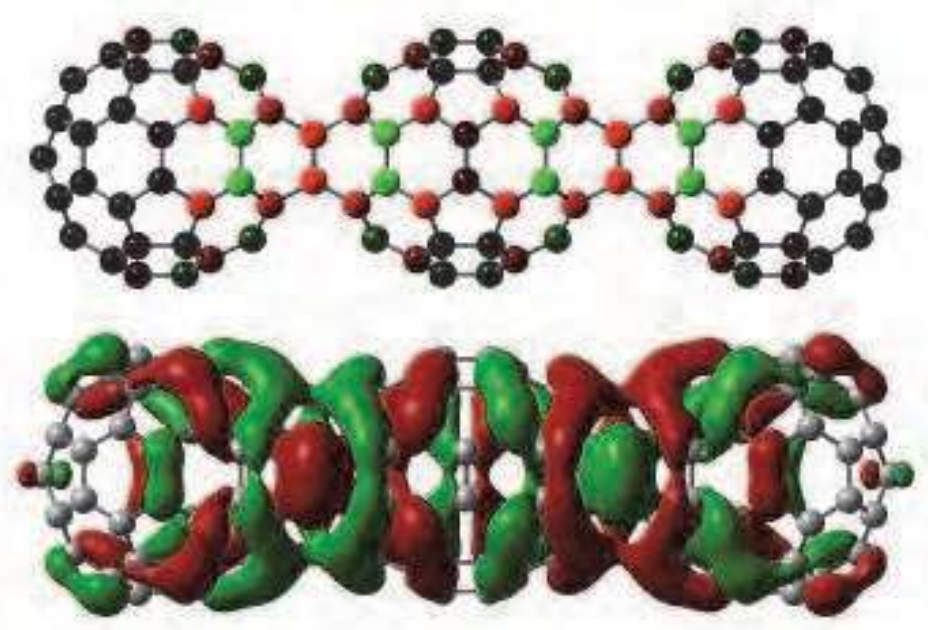

Fig. 14. Geometrical structure and HOMO-orbital (isovalue 0.01 ) of the $\mathrm{C}_{2 \mathrm{~h}}$ symmetry $\mathrm{C}_{60}$ trimer, $\left(\mathrm{C}_{60}\right)_{3}$ based on the $\mathrm{P} 4$ peanut. (Rue (2006))

\begin{tabular}{llll}
\hline${ }_{14} \mathrm{~N} @ \mathrm{C}_{60}-\mathrm{SWCNT}$ & HOMO $(\mathrm{eV})$ & LUMO $(\mathrm{eV})$ & $E_{g}(\mathrm{eV})$ \\
\hline$(14,0)$ & -5.23 & -4.36 & 0.87 \\
$(13,13)$ & -2.02 & -1.25 & 0.77 \\
$(10,10)$ & -5.88 & -5.47 & 0.40 \\
$(9,9)$ & -4.05 & -2.89 & 1.16 \\
\hline $\mathrm{SWCNT}$ & & & \\
\hline$(13,13)$ & -4.06 & -2.86 & 1.20 \\
$(10,10)$ & -5.90 & -5.49 & 0.41 \\
$(9,9)$ & -4.08 & -2.84 & 1.24 \\
\hline$\left(14 \mathrm{~N} @ \mathrm{C}_{60}\right)_{2}-\mathrm{SWCNT}$ & & \\
$(9,9)$ & -3.01 & 0.71 & 3.72 \\
\hline$\left(14 \mathrm{~N} @ \mathrm{C}_{60}\right)_{2}$ & -5.95 & -3.84 & 2.11 \\
${ }_{14} \mathrm{~N} @ \mathrm{C}_{60}$ & -6.60 & -3.57 & 3.03 \\
$\mathrm{C}_{59} \mathrm{~N}$ & -4.58 & -3.29 & 1.29 \\
\hline
\end{tabular}

Table 2. Comparison of $\mathrm{N} @ \mathrm{C}_{60}-\mathrm{SWCNT}$, $\left(\mathrm{N} @ \mathrm{C}_{60}-\mathrm{SWCNT}\right)_{2}, \mathrm{SWCT}$, $\left(\mathrm{N} @ \mathrm{C}_{60}\right)_{2}, \mathrm{~N} @ \mathrm{C}_{60}$, and $\mathrm{C}_{59} \mathrm{~N}$ on energy levels (Suzuki, et. al. (2010)) 


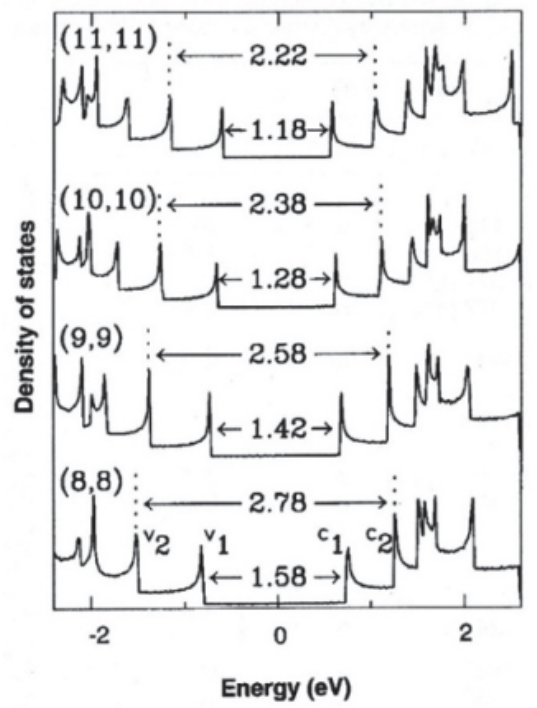

Fig. 15. Electronic density of states (DOS) calculated with a tight binding model for SWCNT armchair $(8,8),(9,9),(10,10)$, and $(11,11)$. The Fermi energy is located at $0 \mathrm{eV}$. Wave vectorconserving optical transitions can occur between mirror image spikes, that is, $v_{1} \rightarrow c_{1}$ and $v_{2} \rightarrow c_{2}$. (Rao, et al. (1997))

\begin{tabular}{lccll}
\hline $\begin{array}{l}\text { Excited state } \\
\mathrm{MO}\end{array}$ & Coefficient & $\begin{array}{c}\text { Energy } \\
(\mathrm{eV})\end{array}$ & $\begin{array}{l}\text { Wavelength } \\
\mathrm{cal} .(\mathrm{nm})\end{array}$ & $\begin{array}{l}\text { Oscillator } \\
\text { Strength }\end{array}$ \\
\hline $\mathrm{\alpha HOMO} \rightarrow$ LUMO & 0.688 & 0.728 & 1703 & 0.0001 \\
$\beta \mathrm{HOMO} \rightarrow$ LUMO & 0.687 & & & 0.0007 \\
\hline$\beta \mathrm{HOMO}-1 \rightarrow$ LUMO & 0.725 & 1.169 & 1061 & \\
$\beta \mathrm{HOMO}-1 \rightarrow$ LUMO & 0.666 & & & \\
\hline
\end{tabular}

Table 3. Excited state transitions of $\mathrm{N}_{0} \mathrm{C}_{60}-\mathrm{SWCNT}(9,9)$, calculated by TD-DFT. (Suzuki, et. al. (2010))

Excited state transitions of $\mathrm{N} @ \mathrm{C}_{60}-\mathrm{SWCNT}$ were investigated by TD-DFT quantum calculation. Table 3 list excited state transitions of $N @ \mathrm{C}_{60}-\mathrm{SWCNT}(9,9)$, calculated by TDDFT. The wavelength converted from the exited energy levels were estimated to be $1703 \mathrm{~nm}$ and $1061 \mathrm{~nm}$, which were closed to experimental results of $\mathrm{C}_{59} \mathrm{~N}-\mathrm{SWCNT}$ by UV-vis NIR spectra and 2D PL contour maps as shown in Fig. 16 (a) (Iizumi, et. al. 2010). The optical behavior displayed the broad peaks around $2000 \mathrm{~nm}$ and $1000 \mathrm{~nm}$, which could be assigned as the first $\left(E_{11} \mathrm{M}\right)$ and second $\left(E_{22} \mathrm{M}\right)$ van Hove transition on Raman spectroscopy with density of state using tight binding model (Rao, et al. 1997). As showed in Fig. 16 (b), the 2D PL contour maps of $\left(\mathrm{C}_{59} \mathrm{~N}\right)_{2}$-SWCNT demonstrated that the emission and excited wavelength were around $1730 \mathrm{~nm}$ and $1000 \mathrm{~nm}$. The slight different value between theoretical and experimental results would be originated in narrowing band gap based on molecular interaction between $\mathrm{N}_{0} \mathrm{C}_{60}$ and SWCNT. 


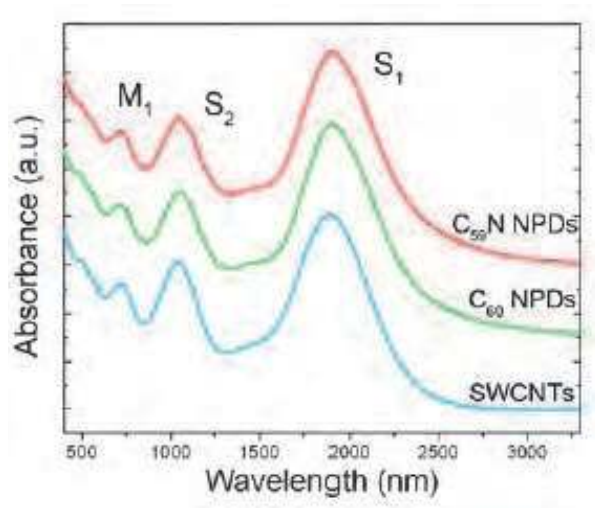

a)

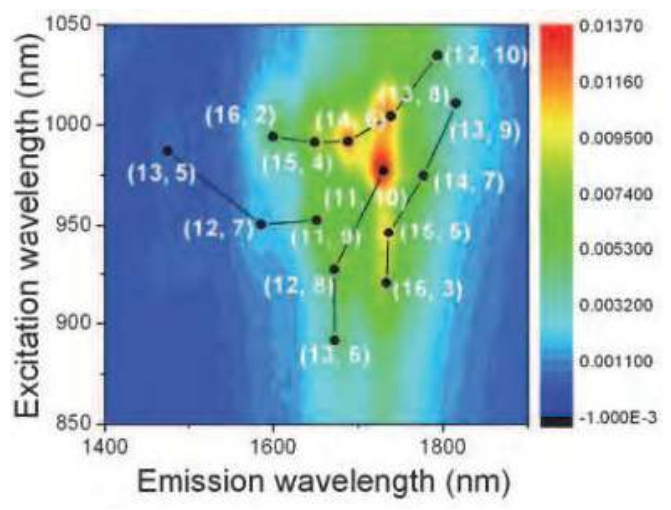

b)

Fig. 16. a) UV-vis NIR spectra, b) 2D PL contour maps of NC59-SWCNT. (Iizumi et. al. (2010))
(a) ${ }^{14} \mathrm{~N} @ \mathrm{C}_{60}-\mathrm{SWCNT}(13,13)$
(b) $\operatorname{SWCNT}(13,13)$

\begin{tabular}{|c|c|c|c|c|c|}
\hline Atom & \multicolumn{2}{|c|}{$\delta(\mathrm{ppm}) / \mathrm{TMS}$} & \multicolumn{3}{|c|}{$\delta(\mathrm{ppm}) / \mathrm{TMS}$} \\
\hline \multirow[t]{11}{*}{$\mathrm{C}$} & 84.86 & 39.0 & $\mathrm{C}$ & 71.83 & 1.0 \\
\hline & 84.58 & 9.0 & & 71.46 & 51.0 \\
\hline & 84.39 & 2.0 & & 62.98 & 52.0 \\
\hline & 84.26 & 8.0 & & 60.70 & 2.0 \\
\hline & 84.14 & 2.0 & & 60.49 & 24.0 \\
\hline & 68.00 & 1.0 & \multicolumn{3}{|c|}{ (c) ${ }^{14} \mathrm{~N} @ \mathrm{C}_{60}$} \\
\hline & 67.77 & 51.0 & $\mathrm{C}$ & 78.14 & 60 \\
\hline & 62.58 & 26.0 & & & \\
\hline & 57.71 & 1.0 & & & \\
\hline & 57.51 & 47.0 & & & \\
\hline & 57.30 & 4.0 & & & \\
\hline
\end{tabular}

Table 4. Chemical shifts of ${ }^{13} \mathrm{C}$ with multicity in ${ }^{14} \mathrm{~N} @ \mathrm{C}_{60}-\mathrm{SWCNT}$, SWCNT and ${ }^{14 N} @ \mathrm{C}_{60}$ (Suzuki et. al. (2010)) 

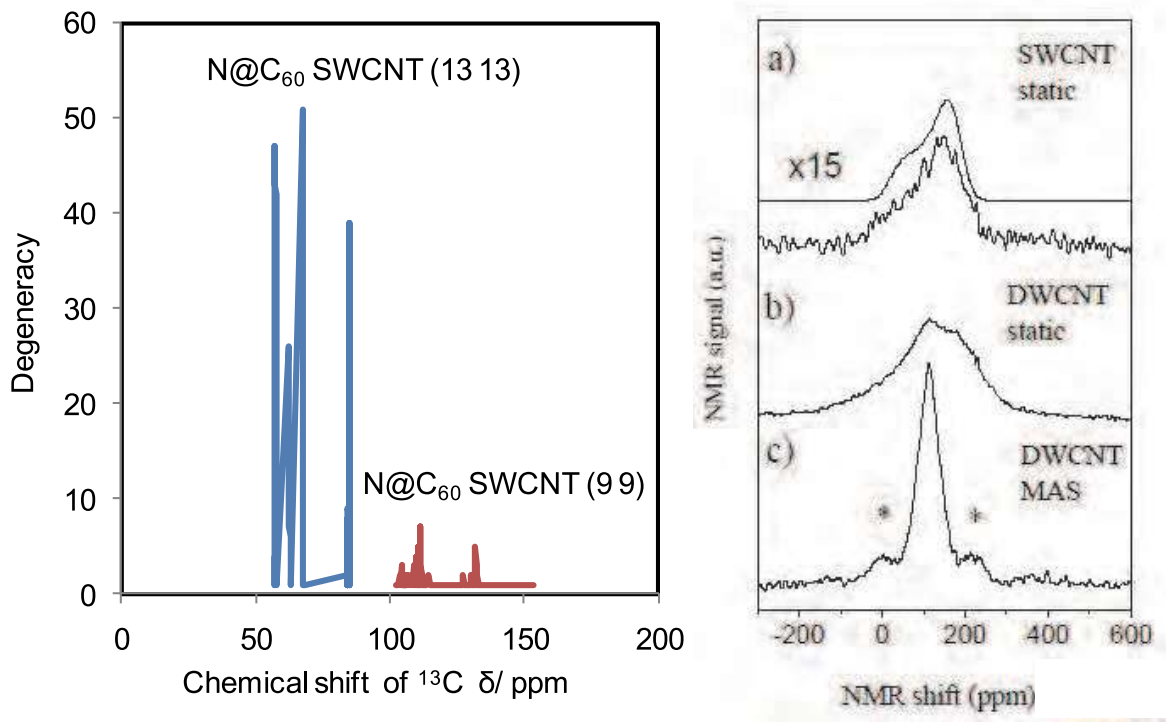

Fig. 17. The measured chemical shift of (a) SWCNT, (b) and (c) DWCNT (Simon et. al. (2007)).

\subsection{Magnetic properties of $\mathbf{N} @ \mathrm{C}_{60}-\mathrm{SWCNT}, \mathrm{N} @ \mathrm{C}_{60}$ and $\mathrm{C}_{59} \mathrm{~N}$.}

The magnetic parameters of chemical shift, principle g-tensor, A-tensor in hyperfine coupling constant (hfc) of $\mathrm{N} @ \mathrm{C}_{60}-\mathrm{SWCNT}$ and $\mathrm{N} @ \mathrm{C}_{60}$ have been studied by NMR, electron paramagnetic resonance (EPR) and electron nuclear double resonance (ENDOR) spectroscopy (Simon, et. al. 2006, 2007). Especially, chemical shifts of ${ }^{13} \mathrm{C}$ with multicity of $\mathrm{N} @ \mathrm{C}_{60}-\mathrm{SWCNT}(13,13), \mathrm{N} @ \mathrm{C}_{60}$ and original SWCNT have been investigated. Table 4 lists chemical shifts of ${ }^{13} \mathrm{C}$ with multicity in ${ }^{14} \mathrm{~N} @ \mathrm{C}_{60}-\mathrm{SWCNT},{ }^{14} \mathrm{~N} @ \mathrm{C}_{60}$ and SWCNT. Comparison results of the chemical shift between $\mathrm{N} @ \mathrm{C}_{60}-\mathrm{SWCNT}$, SWCNT and $\mathrm{N} @ \mathrm{C}_{60}$ were investigated. As listed in Table 4, line position of $\mathrm{N} @ \mathrm{C}_{60}-\mathrm{SWCNT}$ shifted out at degenerated position with 39, 51, 26, 47 multicity states in a low magnetic field. Effect of chiral index on the chemical shifts of ${ }^{13} \mathrm{C}$ in ${ }^{14} \mathrm{~N} @ \mathrm{C}_{60}-\mathrm{SWCNT}$ is shown in Fig. 17. The chemical shifts positions of $\mathrm{N} @ \mathrm{C}_{60}-\mathrm{SWCNT}$ shifted out with decreasing the diameters. The calculated results were considerably closed to the experimental results (Simon, et. al. 2007). These results were originated in a lack of $2 \mathrm{~s}$ spin density distribution, spin-local orbital interaction and $\Pi$ electron interaction between $\mathrm{N} @ \mathrm{C}_{60}$ and inner surface on SWCNT. The electronic spinnuclear spin interaction based on unsymmetrical distribution of $2 \mathrm{p}$ spin orbital influenced the chemical shift position separated with splitting lines under a low magnetic field.

The chemical shifts of ${ }^{13} \mathrm{C}$ with multicity in optimized molecular structure will be calculated. The chemical shift will be constructed with a total sum of four terms as below:

$$
\sigma=\sigma^{\mathrm{dia}}+\sigma^{\mathrm{para}}+\sigma^{\mathrm{FC}}+\sigma^{\mathrm{SD}}
$$

where $\sigma^{\text {dia }}$ is diamagnetic term, opara is paramagnetic term, $\sigma^{\mathrm{FC}}$ is Fermi contact interaction, $\mathrm{o}^{\mathrm{SD}}$ is spin dipole-interaction with angle dependence on $2 \mathrm{p}$ spin density distribution. The magnetic behavior of the chemical shift will be mainly based on the diamagnetic term and 
the spin-dipole interaction. Especially, the chemical shifts of $\mathrm{N}_{0} \mathrm{C}_{60}-\mathrm{SWCNT}$ compared with $\mathrm{C}_{59} \mathrm{~N}$ and $\left(\mathrm{C}_{59} \mathrm{~N}\right)_{2}$ have been quantitatively analyzed on the basis of the experiment using $a b$ initio DFT calculation.

(a) HOMO

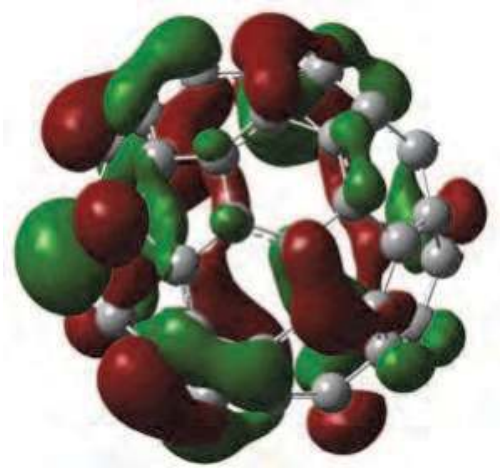

HOMO $-4.58 \mathrm{eV}$

$E_{g}=1.29 \mathrm{eV}$ (b) LUMO

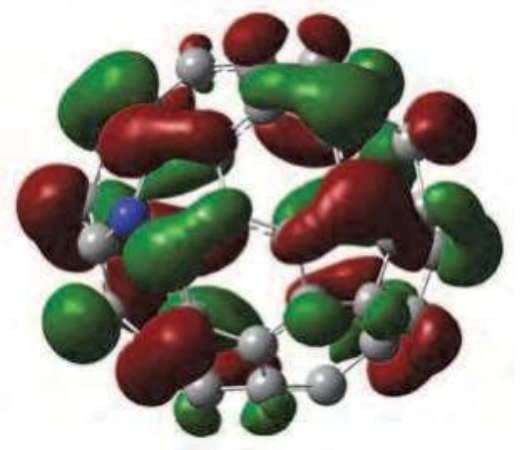

LUMO

$-3.29 \mathrm{eV}$

Fig. 18. Electronic structure of $\mathrm{C}_{59} \mathrm{~N}$ at (a) $\mathrm{HOMO}$ and (b) LUMO. (Suzuki et. al. (2010))

Electronic structure and calculated chemical shifts of ${ }^{13} \mathrm{C}$ and multicity in parentheses for the atoms in the close environment in $\mathrm{C}_{59} \mathrm{~N}$ are shown in Fig. 18 and 19. The calculated chemical shifts of ${ }^{13} \mathrm{C}$ in $\mathrm{C}_{59} \mathrm{~N}$ separated in the range of $126 \mathrm{ppm}$ and $152 \mathrm{ppm}$. The chemical shift of $\mathrm{C}$ near $\mathrm{N}$ atom suggests at $136.22 \mathrm{ppm}$ with multicity at 5.0. The behavior would be arisen from electron-nuclear spin interaction based on spin density distribution at HOMO. The ${ }^{13} \mathrm{C}$ chemical shifts of $\left(\mathrm{C}_{59} \mathrm{~N}\right)_{2}$ compared them with the experimental spectrum. Comparison
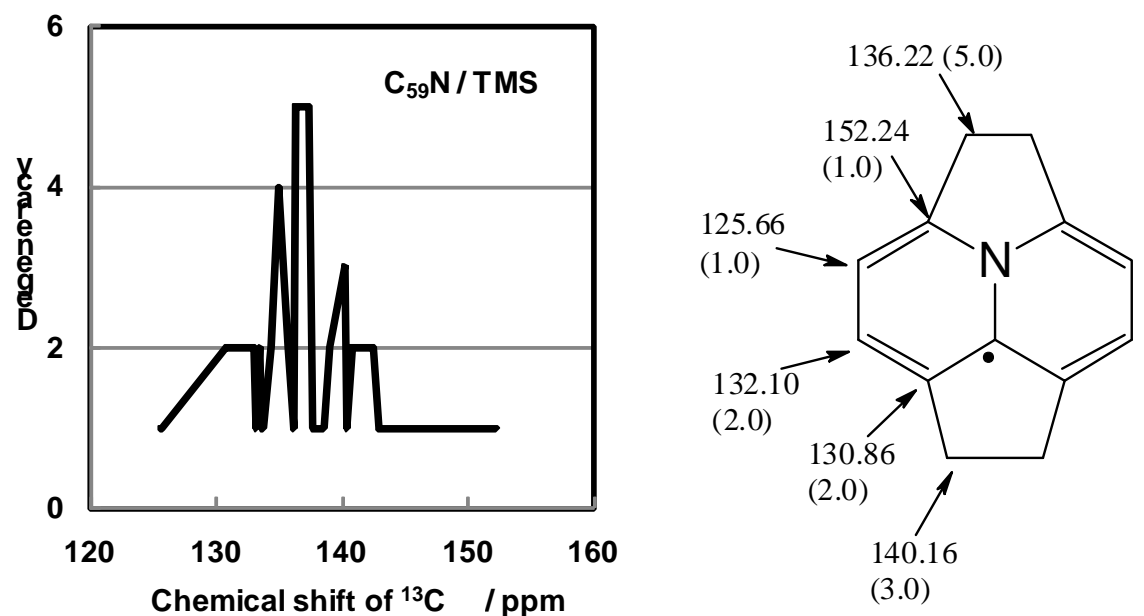

Fig. 19. Calculated chemical shifts of ${ }^{13} \mathrm{C}$ and multicity in parentheses for the atoms in the close environment in $\mathrm{C}_{59}$ N. (Suzuki et. al. (2010)) 
between the calculated ${ }^{13} \mathrm{C}$ chemical shifts of $\left(\mathrm{C}_{59} \mathrm{~N}\right)_{2}$ and the experimental spectrum is showed in Fig. 20. The value for the saturated carbon atom $\left(C^{\prime}\right), 83.1 \mathrm{ppm}$, is refined to 85.3 ppm with the TZP/DZ basis, is in reasonably good agreement with the experiment $(90.3$ $\mathrm{ppm}$ ), as is the value for the corresponding carbon atom in $\mathrm{C}_{59} \mathrm{NNH}, 68.4 \mathrm{ppm}$ (TZP/DZ) versus 72.1. Figure 21 shows ${ }^{13} \mathrm{C}$ chemical shifts for the atoms in the close environment of $\mathrm{N}$ : (a) $\left(\mathrm{C}_{59} \mathrm{~N}\right)_{2}$, (b) $\mathrm{C}_{59} \mathrm{NH}$, and (c) indole. There was a substantial de-shielding of the saturated carbon atom in going from $\mathrm{C}_{59} \mathrm{NH}$ to $\left(\mathrm{C}_{59} \mathrm{~N}\right)_{2}$, both in the experimental and theoretical data using the electronic density distribution.

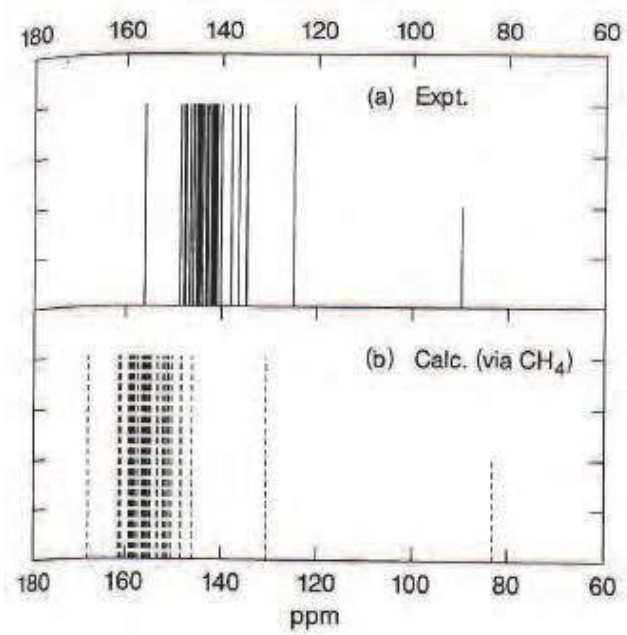

Fig. 20. ${ }^{13} \mathrm{C}$ chemical shifts $\left(\mathrm{C}_{59} \mathrm{~N}\right)_{2}$ : (a) experimental spectrum and (b) computed values at the DZ level (Buhl et. al. (1997))
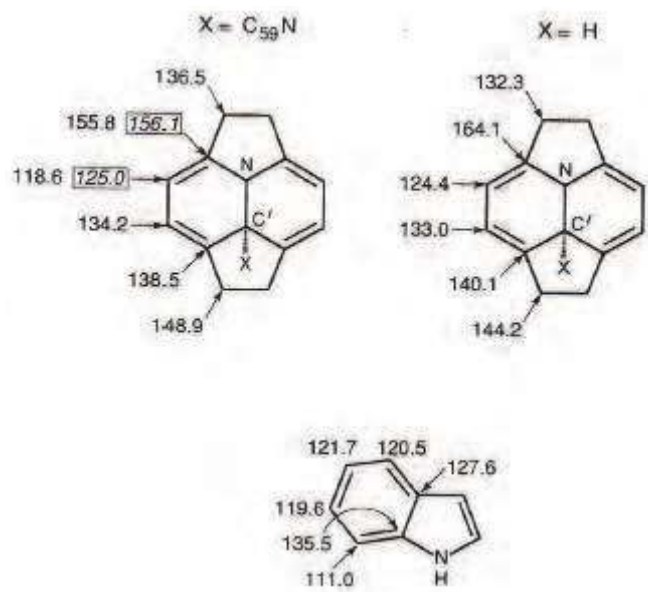

Fig. $21 .{ }^{13} \mathrm{C}$ chemical shifts for the atoms in the close environment of $\mathrm{N}$ : (a) $\left(\mathrm{C}_{59} \mathrm{~N}\right)_{2},(\mathrm{~b})$ $\mathrm{C}_{59} \mathrm{NH}$, and (c) indole. Experimental data are in boxes. Note that in the three cases the location and magnitude of the "extrema" are similar (Buhl et. al. (1997)) 
The magnetic interaction with the electron spins will be explained. The Hamiltonian can be formulated by Eq. (2).

$$
H=g \beta_{e} S H-g_{N} \beta_{N} I H+S A I+S D S+I Q I
$$

The five terms represent the following interactions: electronic and nuclear Zeeman interaction, the hyperfine of the spin nuclear interaction, the fine structure of the spin-spin interaction and the nuclear quadrupole.

Energy level diagram for isotropic atomic ${ }^{14} \mathrm{~N} @ \mathrm{C}_{60}$ in a strong external magnetic field is shown in Fig. 22 (A). This Hamiltonian yields the 12-level system illustrated in Fig. 22 (A). The first split shows the four possible values of the electronic spin, and these are each split into the three possible values of I. The splitting of the nuclear energy levels has been investigated. The principle value of g-tensor will be mainly estimated by second perturbation. $\Delta \mathrm{g}_{\mathrm{ii}}$ related to spin local interaction with energy interaction between paramagnetic and nearest neighbor interaction.

$$
\begin{gathered}
\mathrm{g}_{\mathrm{ii}}=\mathrm{g}_{\mathrm{e}}+\Delta \mathrm{g}_{\mathrm{ii}} \\
g_{i i}=g_{e}\left\{1+\sum_{\mathrm{m}} \frac{\left|\varphi_{\mathrm{m}}\right| \mathrm{L}_{\mathbf{i}}\left|\varphi_{\mathrm{p}}\right|^{2}}{\epsilon_{\mathrm{p}}-\epsilon_{\mathrm{m}}}\right\} \\
\Delta g_{i i}=g_{i i}-2=\frac{\zeta a}{\Delta E_{i}}
\end{gathered}
$$

The hyperfine coupling strength of A-tensor is constructed with a sum of isotropic and anisotropic hyperfine interaction.

$$
\begin{gathered}
\text { A-tensor }=A_{i s o}+A^{\prime}{ }_{i i} \\
A_{i s o}=8 \pi / 3 g_{n} \mu_{N} \rho(0) \\
A^{\prime}{ }_{i i}=g_{N} \mu_{N} \int \frac{\left(3 \cos ^{2} \theta-1\right)}{\mathbf{r}^{3}} \rho(\mathbf{r}) \mathrm{d} v
\end{gathered}
$$

The isotropic hyperfine interaction, $\mathrm{A}_{\text {iso }}$ will be related on the $2 \mathrm{~s}$ spin density distribution, $\rho(0)$, as described by Eq. (7). The anisotropic hyperfine interaction, $\mathrm{A}^{\prime}{ }_{\mathrm{ii}}$-tensor has influence of the $2 p$ spin density distribution with angle dependence on a direction of the electron nuclear interaction, as noted in Eq. (8). A quantitative relation between the $\pi$-electron spin density and the isotropic hyperfine coupling constant has been discussed. For planar $\pi$-radical (e.g., $\mathrm{CH}_{3}$ radical), this relation has been known as noted by Eq. (9).

$$
A_{\text {iso }}=Q \rho^{\pi}
$$

where $\rho^{\pi}$ is the $\pi$-electron density on the $C$ atom and $Q=45 \mathrm{G}$. A future of non-planar radicals including $\mathrm{C}_{59} \mathrm{~N}$ is the "umbrella effect characterized by (i) deviation of the $\mathrm{C}$ atom containing the unpaired electron from the plane and (ii) partial change in the hybridization of this $C$ atom, which becomes intermediate between $\mathrm{sp}^{2}$ and $\mathrm{sp}^{3}$ (Abronin et. al. 2004). The spin-spin interaction with zero field constant, S D S is mainly originated in the dipole-dipole 
interaction, as noted by fifth term in Eq. (2). In the quadruple nuclear interaction, I Q I, the quadruple coupling constant, $Q$ of nitrogen atom with more than $I=1$ on nuclear quadruple resonance (NQR) will be dependence on magnetic interaction between electric quadruple moment, e $\mathrm{Q}$ and electric field gradient (EFG). The electric quadruple moment, e $\mathrm{Q}$ will be related on deviation of nuclear charge distribution. The magnetic parameters of g-tensor, Atensor in the hyperfine coupling constant and the quadruple coupling constant of nitrogen atom will be under the spin nuclear interaction, e Q, EFG and the spin density distribution.
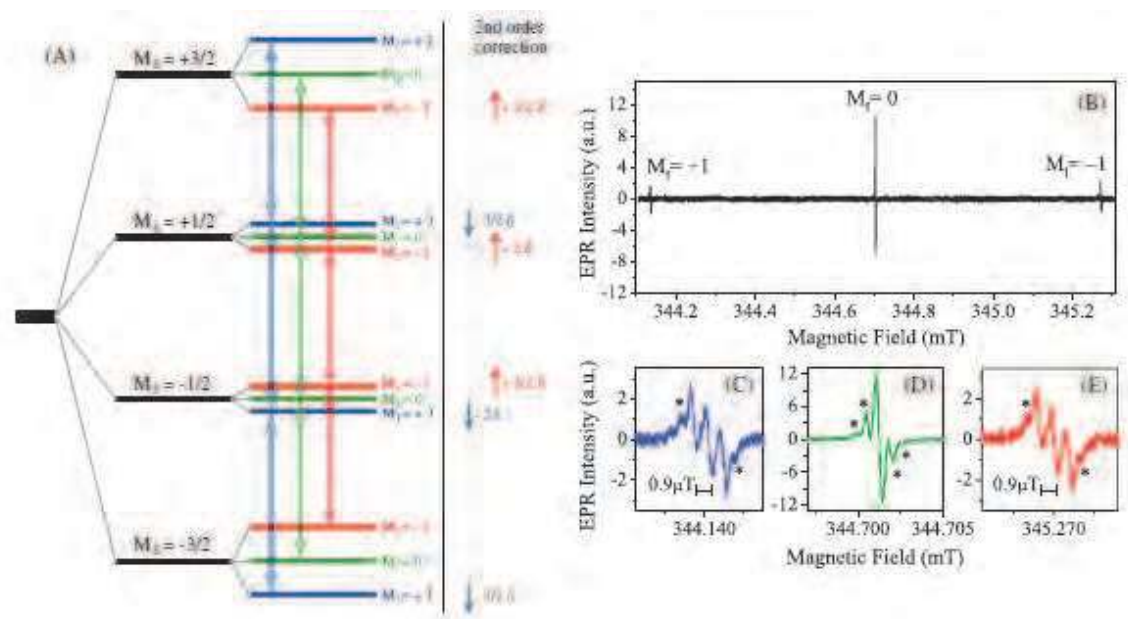

Fig. 22. (A) ${ }^{14} \mathrm{~N} @ \mathrm{C}_{60}$ has electron spin $S=3 / 2$ and nuclear spin $I=1$ which together provide a rich 12-level structure. Considering only the first-order hyperfine interaction, the three electron transitions associated with a particular nuclear spin projection are degenerate. Adding the second order corrections $(\delta=a 2 / B)$ lifts the degeneracies for the $M I= \pm 1$ lines. (B) Continuous wave EPR spectrum of high purity $\mathrm{N} @ \mathrm{C}_{60}$ in degassed $\mathrm{CS}_{2}$ at room temperature. Each line in the triplet signal is labeled with the corresponding projection $M I$ of the ${ }^{14} \mathrm{~N}$ nuclear spin. (C-E) Zoom-in for each of the three hyperfine lines reveals further structure. Stars $\left({ }^{*}\right)$ mark the line split by ${ }^{13} \mathrm{C}$ hyperfine interactions with $\mathrm{C}_{60}$ cage. Measurement parameters: microwave frequency, $9.67 \mathrm{GHz}$; microwave power, $0.5 \mu \mathrm{W}$; modulation amplitude, $0.2 \mu \mathrm{T}$; modulation frequency, $1.6 \mathrm{kHz}$. (Simon et. al. (2006))

\subsection{Calculated magnetic parameters}

The EPR spectrum of ${ }^{14} \mathrm{~N}$ inside $\mathrm{N} @ \mathrm{C}_{60}$ consists of three lines centered at electron g-factor, split by a ${ }^{14} \mathrm{~N}$ isotropic hyperfine interaction. Table 6 lists magnetic parameters of g-tensor, A-tensor in hfc and Mulliken N atomic charge of $\mathrm{N} @ \mathrm{C}_{60}-\operatorname{SWCNT}(13,13),(9,9),\left(\mathrm{N} @ \mathrm{C}_{60}\right)_{2}$, $\mathrm{N} @ \mathrm{C}_{60}$ and $\mathrm{C}_{59} \mathrm{~N}$, calculated by ab-nitio DFT quantum calculation. The magnetic parameters such as principal g-tensor, hfc and Mulliken N atomic charges in N@ $\mathrm{C}_{60}-\mathrm{SWCNT}(9,9)$ were estimated to be $2.00093-98,3.8-6.0$ and $3.8 \times 10^{-5}$, respectively. The calculated magnetic parameters of $\mathrm{N} @ \mathrm{C}_{60}-\mathrm{SWCNT}$ were discussed on the basis of the experimental results as shown in Fig. 23. The slight un-symmetrical values of hfs on $\mathrm{N} @ \mathrm{C}_{60}-\mathrm{SWCNT}$ would be originated in anisotropy spin-dipole interaction and $\Pi$ electron interaction between $\mathrm{N} @ \mathrm{C}_{60}$ and inner surface on SWCNT. In this case, a few percent of the values of $\rho(2 s)$ and $\rho(2 p)$ on nitrogen in $\mathrm{N} @ \mathrm{C}_{60}-\mathrm{SWCNT}$ will be expected by the values of $\mathrm{A}_{\mathrm{N}}(2 \mathrm{~s})$ and $(2 \mathrm{p})$ of ${ }^{14} \mathrm{~N}$ to 
be $557 \mathrm{G}$ and $17.8 \mathrm{G}$ at the $\rho(2 \mathrm{~s})=1$ and $\rho(2 \mathrm{p})=1$. The calculated values of hfs in $\mathrm{N} @ \mathrm{C}_{60^{-}}$ SWCNT, $\mathrm{N} @ \mathrm{C}_{60}$ and $\mathrm{C}_{59} \mathrm{~N}$ was in proportion to the spin-dipole interaction, a few percent of contribution from the $2 \mathrm{p}$ spin density distribution with a lack of $2 \mathrm{~s}$ spin density distribution, obeyed by Fermi contact parts. The nuclear quadruple interaction of ${ }^{14} \mathrm{~N}(\mathrm{I}=1)$ in $\mathrm{N} @ \mathrm{C}_{60}-$ SWCNT was negligible due to a slight value of EFG based on charge transfer from the CNT to $\mathrm{C}_{60}$ with a slight value of the Mulliken atomic charges. The principle g-tensor, hfc and Mulliken nitrogen atomic charges on $\mathrm{N} @ \mathrm{C}_{60}-\mathrm{SWCNT}(9,9)$ as compared with $\mathrm{N} @ \mathrm{C}_{60}$ and $\mathrm{C}_{59} \mathrm{~N}$ were decreased. These results would be dependence with geometrical effects of $\mathrm{N} @ \mathrm{C}_{60}-\mathrm{SWCNT}(\mathrm{n}, \mathrm{n})$ for chiral index on $\Pi$-electron interaction in cooperation with the magnetic interaction between electron spins, $S=3 / 2$ and nuclear spin, $I=1$.

Experimental values of A-tensor in hfs on $\mathrm{N} @ \mathrm{C}_{60}$ and $\mathrm{C}_{59} \mathrm{~N}$ are shown in Fig. 23 and 24. The symmetrical structure of $\mathrm{N} @ \mathrm{C}_{60}$ had isotropic value of magnetic parameters. The experimental results of $\mathrm{N} @ \mathrm{C}_{60}$ compared with $\mathrm{C}_{59} \mathrm{~N}$ (Fulop et. at. (2001)) were considerably closed to the calculated results (Harneit et. al. (2002)). The unsymmetrical structure of $\mathrm{C}_{59} \mathrm{~N}$ affected the principle lines at several states, which splitting by anisotropy hyperfine interaction. Spin density distribution of paramagnetic azafullerene, $\mathrm{C}_{59} \mathrm{~N}$ have been calculated (Abronin et. al. 2004, Schrier et. al. 2006). Based on hyperfine coupling constants for ${ }^{14} \mathrm{~N}$ and ${ }^{13} \mathrm{C}$ nuclei in $\mathrm{C}_{59} \mathrm{~N}$, the spin density distribution of the unpaired $\Pi$-electron in $\mathrm{C}_{59} \mathrm{~N}$ was mainly localized around the nitrogen atom. Mulliken charge transfer of nitrogen atom in $\mathrm{C}_{59} \mathrm{~N}$ was calculated to be -0.6 e. This result indicates a considerable value of charge transfer from $\mathrm{C}_{60}$ to $\mathrm{N}$ atom. The magnetic parameters of the anisotropic molecular structure would be strongly attributed from the spin-dipole interaction with $2 p$ spin density distribution. Considerably, molecular design of the endohedral fullerenes within SWCNT varied with geometry structure is important to control the quantum spin qubit, splitting the magnetic parameters including g-tensor, A-tensor of hfc and the chemical shifts in the NMR quantum computer.

\begin{tabular}{|c|c|c|c|}
\hline Elements & $\begin{array}{c}\text { g-tensor } \\
\left(g_{x x}, g_{y y}, g_{z z}\right)\end{array}$ & $\begin{array}{c}\text { hfc / G } \\
\left(\mathrm{A}_{\mathrm{xx}}, \mathrm{A}_{\mathrm{yy}}, \mathrm{A}_{\mathrm{zz}}\right)\end{array}$ & $\begin{array}{c}\text { Mulliken } \mathrm{N} \text { atomic } \\
\text { charges / e }\end{array}$ \\
\hline $14 \mathrm{~N} @ \mathrm{C}_{60}$ & 2.00119 & 2.4 & \multirow[t]{3}{*}{-0.004521} \\
\hline -SWCNT & 2.00119 & 2.4 & \\
\hline$(13,13)$ & 2.00117 & 1.3 & \\
\hline $14 \mathrm{~N} @ \mathrm{C}_{60}$ & 2.00098 & 6.0 & \multirow{3}{*}{0.000038} \\
\hline -SWCNT & 2.00098 & 6.0 & \\
\hline$(9,9)$ & 2.00093 & 3.8 & \\
\hline$\left(14 \mathrm{~N} @ \mathrm{C}_{60}\right)_{2}$ & 1.99775 & 4.6 & \multirow{3}{*}{$0.004299,0.004381$} \\
\hline Dimmer & 1.99776 & 4.6 & \\
\hline & 1.99785 & 15.0 & \\
\hline${ }^{14} \mathrm{~N} @ \mathrm{C}_{60}$ & 2.00490 & 4.5 & \multirow{3}{*}{0.211512} \\
\hline & 2.00490 & 4.5 & \\
\hline & 2.00490 & 4.5 & \\
\hline $\mathrm{C}_{59} \mathrm{~N}$ & 2.00545 & 2.4 & \multirow{3}{*}{-0.605804} \\
\hline & 2.00511 & 2.5 & \\
\hline & 2.00356 & 7.6 & \\
\hline
\end{tabular}

Table 5. g-tensor, hfc and Mulliken N atomic charge of ${ }^{14} \mathrm{~N} @ \mathrm{C}_{60}-\mathrm{SWCNT}$ (Suzuki et. al. (2010)). 


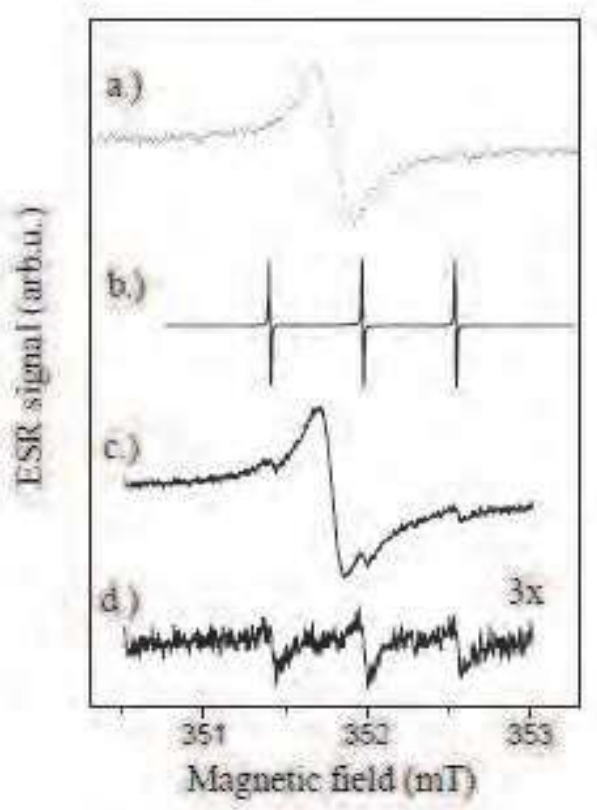

Fig. 23. ESR spectra of (a) SWCNT, (b) N@ $\mathrm{C}_{60}$ and (c)-(d) N@ $\mathrm{C}_{60}-\mathrm{SWCNT}$ at triplet state. (Simon et. al. (2007)).

\begin{tabular}{|c|c|c|c|c|c|c|}
\hline \multirow{3}{*}{$\begin{array}{l}\text { Endohedral } \\
\text { fullerenes }\end{array}$} & \multirow{3}{*}{$\begin{array}{l}\text { Nuclear } \\
\text { spin } \\
\mathrm{I}\end{array}$} & \multirow{3}{*}{$\begin{array}{l}\text { Hyperfine } \\
\text { constant } \\
\mathrm{A}(\mathrm{MHz})\end{array}$} & \multicolumn{4}{|c|}{ Electron spin relaxation in dilute powder } \\
\hline & & & \multicolumn{2}{|c|}{$\mathrm{T}=300 \mathrm{~K}$} & \multicolumn{2}{|c|}{$\mathrm{T}=5 \mathrm{~K}$} \\
\hline & & & $\begin{array}{l}\mathrm{T}_{1} \\
(\mu \mathrm{s}) \\
\end{array}$ & $\begin{array}{l}\mathrm{T}_{2} \\
(\mu \mathrm{s}) \\
\end{array}$ & $\begin{array}{l}\mathrm{T}_{1} \\
(\mathrm{~s}) \\
\end{array}$ & $\begin{array}{l}\mathrm{T}_{2} \\
(\mu \mathrm{s})\end{array}$ \\
\hline${ }^{14} \mathrm{~N} @ \mathrm{C}_{60}$ & 1 & 15.88 & 120 & 20 & $0.5-9 a)$ & 20 \\
\hline${ }^{15} \mathrm{~N} @ \mathrm{C}_{60}$ & $1 / 2$ & 22.26 & 45 & 11 & 1 & 14 \\
\hline $31 \mathrm{P} @ \mathrm{C}_{60}$ & $1 / 2$ & 138.4 & 2.7 & 1.3 & $\left.0.5-8^{a}\right)$ & $14-28 \mathrm{~b})$ \\
\hline
\end{tabular}

a) depending on sample quality

b) depending on endohedral fullerene concentration

Table 6. Spin properties of the endohedral $\mathrm{C}_{60}$ fullerenes with electron spin $\mathrm{S}=3 / 2$ (Harneit et. al. (2002)) 


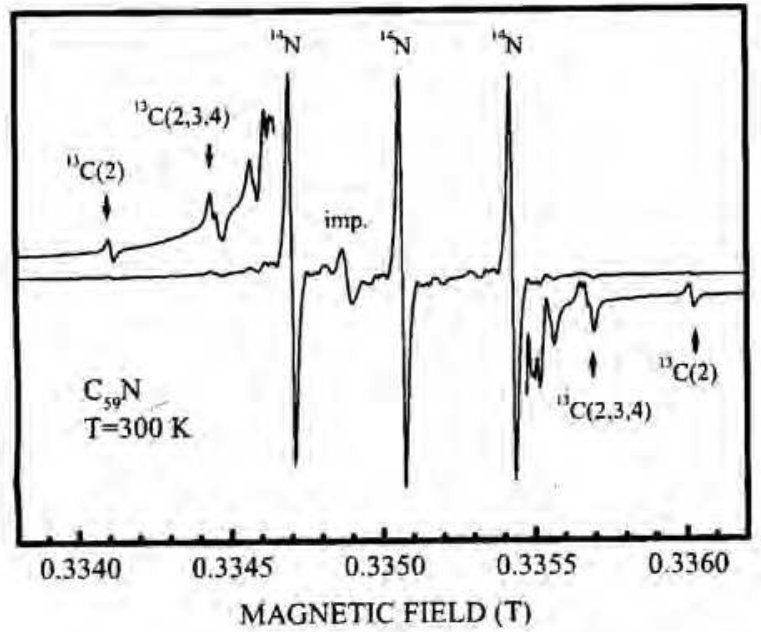

Fig. 24. Motionally narrowed ESR spectrum of tumbling $\mathrm{C}_{59} \mathrm{~N}$ substituted in $\mathrm{C}_{60}$ at $290 \mathrm{~K}$ and $9 \mathrm{GHz}$ (Fulop et. al. (2001)).

\section{Conclusion}

Design of spin labels for the NMR quantum computer that contained 1D spin chains filling SWCNT with $\mathrm{N}_{0} \mathrm{C}_{60}$ has been proposed. The electronic structure, chemical shift, g-tensor, A-tensor of hfc would be influenced by geometrical structure, varied with diameter and chiral index. The magnetic properties were originated in spin density distribution with חelectron interaction between $\mathrm{N} \mathrm{C}_{60}$ and inner surface on SWCNT and CT. The slight unsymmetrical values of A-tensor in hfs on $\mathrm{N} @ \mathrm{C}_{60}-\mathrm{SWCNT}(9,9)$ would be originated in anisotropy spin-dipole interaction and $\Pi$-electron interaction between $\mathrm{N} @ \mathrm{C}_{60}$ and inner surface on SWCNT. The values of A-tensor in hfc would be in proportion to the $2 \mathrm{p}$ spin distribution based on the spin-dipole interaction with a lack of $2 \mathrm{~s}$ spin density distribution, obeyed by Fermi contact parts. The magnetic parameters of the anisotropic structure would be strongly influenced by the spin-dipole interaction with a slight distribution of the $2 \mathrm{p}$ spin density. Molecular design of the endohedral fullerenes within SWCNT as peapods is important to control quantum qubit, splitting the principle lines based on hyperfine interaction as the NMR quantum computer.

\section{References}

\section{NMR quantum computer using $\mathrm{N} @ \mathrm{C}_{60}, \mathrm{P} @ \mathrm{C}_{60}$ and $\mathrm{N} @ \mathrm{C}_{60}-\mathrm{SWCNT}$}

Benjamin, S. C.; Ardavan, A.; Briggs, G. A. D.; Britz, D. A.; Gunlycke, D.; Jefferson, J.; Jones, M. A. G.; Leigh, D. F.; Lovett, B. W.; Khlobystov, A. N.; Lyon, S. A.; Morton, J. J. L.; Porfyrakis, K.; Sambrook, M. R.; Tyryshkin, A. M.; (2006) Towards a fullerenebased quantum computer, J. Phys.: Condens. Matter Vol.18, pp.S867-S883. 
Harneit, W.; Meyer, C.; Widinger, A.; Suter, D.; Twamley, J.; (2002) Architectures for a Spin Quantum Computer Based on Endohedral Fullerenes, phys. stat. sol. (b) Vol. 233, pp. 453-461.

Ju, C.; Suter, D.; Du, J.; (2007) Two-qubit gates between noninteracting qubits in endohedral fullerene-based quantum computation, Phys, Rev. A. Vol. 75, pp. 012318-1-5.

Meyer, C.; Harneit, W.; Naydenov, B.; Lips, K.; Widinger A.; (2004) N@ $\mathrm{C}_{60}$ and P@ $\mathrm{C}_{60}$ as quantum bits, Appl. Magn. Reson. Vol. 27, pp. 123-132.

Morton, J. J. L.; Tyryshkin, A. M.; Ardavan, A.; Benjamin, S. C.; Porfyrakis, K.; Lyon, S. A.; Briggs, G. A. D.; (2005) Bang-bang control of fullerene qubits using ultra-fast phase gates, Nature Physics Vol. 40, pp. 40-44.

Morton, J. J. L.; Tyryshkin, A. M.; Ardavan, A.; Benjamin, S. C.; Porfyrakis, K.; Lyon, S. A.; Briggs, G. A. D.; (2006) The $\mathrm{N} @ \mathrm{C}_{60}$ nuclear spin qubit: Bang-bang decoupling and ultrafast phase gates, phys. stat. sol. (b) Vol.243, pp. 3028-3031.

Brown, R. M.; Tyryshkin, A. M.; Porfyrakis, K.; Gauger E. M.; Lovett, B. W.; Ardavan, A,; Lyon, S. A.; Briggs, G. A. D.; Morton, J. J. L. (2011) Coherent State Transfer between an Electron and Nuclear Spin in ${ }^{15} \mathrm{~N} @ \mathrm{C}_{60}$, Phys. Rev. Lett. Vol. 106, pp. 110504-1-4.

Yang, W. L.; Xu, Z. Y.; Wei, H.; Feng, M.; Suter D.; (2010) Quantum-information-processing architecture with endohedral fullerenes in a carbon nanotube, Phys. Rev. A. Vol. 81, pp.032303-1-8.

\section{$\mathrm{N} @ \mathrm{C}_{60}-\mathrm{SWCNT}$}

Bailey, S. W. D.; Lambert, C. J.; (2007) The electronic transport properties of $\mathrm{N} @ \mathrm{C}_{60} @(\mathrm{n}, \mathrm{m})$ carbon nanotube peapods, Phys. E, Vol.40, pp.99-102.

Cho, Y.; Han, S.; Kim, G.; Lee, H.; Ihm, J.; (2003) Orbital Hybridization and Charge Transfer in Carbon Nanopeapods, Phys. Rev. Lett. Vol. 90, 106402-1-4.

Iizumi, Y.; Okazaki, T.; Liu, Z.; Suenaga, K.; Nakanishi, T.; Iijima, S.; Rotas, G.; Tagmatarchis, N.; (2010) Host-guest interactions in azafullerene $\left(\mathrm{C}_{59} \mathrm{~N}\right)$-single-wall carbon nanotube (SWCNT) peapod hybrid structures, Chem. Commun, Vol. 46, pp.1293-1295.

Simon, F.; Kuzmany, H.; Na’fra’di, B.; Fehe’rr, T.; Forro', L.; Fu“lo“p, F.; Ja'nossy, A.; Korecz, L.; Rockenbauer, A.; Hauke, F.; Hirsch, A.; (2006) Magnetic fullerenes inside singlewall carbon nanotubes, Phys. Rev. Lett. Vol.97, pp.136801-1-4.

Simon, F.; (2007) Studying Single-Wall Carbon Nanotubes Through Encapsulation: From Optical Methods Till Magnetic Resonance, J. Nanoscience and Nanotechnology, Vol.7, pp.1197-1220.

Suzuki, A.; Oku, T.; Kikuchi, K.; (2010) Electronic structure and magnetic properties of ${ }^{14} \mathrm{~N} @ \mathrm{C}_{60}$ within single-walled carbon nanotube as peapods, Physica B, Vol. 405, pp.2418-2422.

Tooth, S.; Quintavalle, D.; Náfrádi, B.; Forró, L.; Korecz, L.; Rockenbauer, A.; Kálai, T.; Hideg, K.; Simon, F.; (2008) Stability and electronic properties of magnetic peapods, Phys. Stat. Solids. (B) Vol.245, pp.2034-2037.

\section{Sc@C $82-S W C N T$}

Cantone, A. L.; Buitelaar, M. R.; Smith, C. G.; Anderson, D.; Jones, G. A. C.; Chorley, S. J.; Casiraghi, C.; Lombardo, A.; Ferrari, A. C.; Shinohara, H.; Ardavan, A.; Warner, J.; Watt, A. A. R.; Porfyrakis, K.; Briggs, G. A. D.; (2008) Electronic transport 
characterization of $\mathrm{Sc}_{8} \mathrm{C}_{82}$ single-wall carbon nanotube peapods, J. App. Phys. Vol.104, pp.083717-1.

Warner, J. H.; Watt, A. A. R.; Ge, L.; Porfyrakis, K.; Akachi, T.; Okimoto, H.; Ito, Y.; Ardavan, A.; Montanari, B.; Jefferson, J. H.; Harrison, N. M.; Shinohara, H.; Briggs, G. A. D.; (2008) Dynamics of Paramagnetic Metallofullerenes in Carbon Nanotube Peapods, Nano Lett. Vol.8, pp.1005-1010.

\section{Carbon tubes}

Khlobystrov, A. N.; Britz, D. A.; Andrew, G.; Briggs, D.; (2005) Molecules in carbon nanotubes, Acc. Chem. Res. Vol.38, pp.901-909.

Rao, A. M.; Richter, E.; Bandow, S.; Chase, B.; Eklund, P. C.; Williams, K. A.; Fang, S.; Subbaswamy, K. R.; Menon, M.; Thess, A.; Smalley, R. E.; Dresselhaus, G.; Dresselhaus, M. S.; (1997) Diameter-Selective Raman Scattering from Vibrational Modes in Carbon Nanotubes Science, Vol. 275, pp.187-191.

$\mathrm{N} @ \mathrm{C}_{60}, \mathbf{P} @ \mathrm{C}_{60}, \mathrm{C}_{60},\left(\mathrm{C}_{59} \mathrm{~N}\right)_{2}$ and $\mathrm{C}_{59} \mathrm{~N}$

Abronin, I. A.; Breslavskaya, N. N.; Rakitina, V. A.; Buchachenko, A. L.; (2004) Spin density distribution in paramagnetic azafullerene: Russ. Chem. Bull. Int. Ed. Vol. 53, pp. 2475-2477.

Andreoni, W.; Curioni, A.; Holczer, K.; Prassides, K.; Keshavarz-K., M.; Hummelen, J.; Wudl, F.; (1996) Unconventional Bonding of Azafullerenes: Theory and Experiment, J. Am. Chem. Soc. 118, pp. 11335 - 11336.

Beu, T. A.; (2006) Electronic structure calculations of peanut-shaped $\mathrm{C}_{60}$ polymers, J. Opt. Adv. Mat. Vol. 8, pp.177 - 180.

Buhl, M.; Curioni A.; Andreoni, W.; (1997) Chemical shifts of diamagnetic azafullerens: $\left(\mathrm{C}_{59} \mathrm{~N}\right)_{2}$ and $\mathrm{C}_{59} \mathrm{NH}$, Chem. Phys. Lett. pp. 231-234.

Fulop, F.; Rockenbauer, A.; Simon, F.;Pekker, S.; Korecz, L.; Garaji, S., Janossy. Andrais; (2001) Azafullerene $\mathrm{C}_{59} \mathrm{~N}$, a stable free radical substituent in crystalline $\mathrm{C}_{60}$ : Chem. Phys. Lett. Vol. 334, pp. 233-237.

Kobayashi K.; Nagase S.; Dinse K.; (2003) A theoretical study of spin density distributions and isotropic hyperfine couplings of $\mathrm{N}$ and $\mathrm{P}$ atoms in $\mathrm{N} @ \mathrm{C}_{60}, \mathrm{P} @ \mathrm{C}_{60}, \mathrm{~N} @ \mathrm{C}_{70}$, $\mathrm{N} @ \mathrm{C}_{60}\left(\mathrm{CH}_{2}\right)_{6}$, and $\mathrm{N} @ \mathrm{C}_{60}\left(\mathrm{SiH}_{2}\right)_{6}:$ Chem. Phycs. Lett. pp 93-98

Schiller, F.; Ruiz-Osés, M.; Ortega, J. E.; Segovia, P.; Martínez-Blanco, J.; Doyle, B. P.; PérezDieste, V.; Lobo, J.; Néel, N.; Berndt, R.; Kröger, J.; (2006) Electronic structure of $\mathrm{C}_{60}$ on $\mathrm{Au}(887)$, J. Chem. Phys. Vol. 125, pp.144719-1-6.

Schrier, J.; Whaley, K. B.; (2006) Hyperfine coupling constants of the azafulleenes $\mathrm{C}_{19} \mathrm{~N}$, $\mathrm{C}_{59} \mathrm{~N}, \mathrm{C}_{69} \mathrm{~N}$, and $\mathrm{C}_{75} \mathrm{~N}$ : J. Phys. Chem. A Vol. 110, pp. 5386-5390.

Schulte, K.; Wang, L.; Moriarty, P. J.; Prassides, K.; Tagmatarchis, N.; (2007) Resonant processes and Coulomb interactions in $\left(\mathrm{C}_{59} \mathrm{~N}\right)_{2}$, J. Chem. Phys. Vol. 126, 184707184713. 


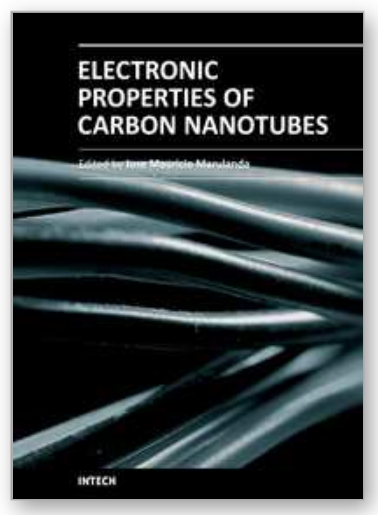

\author{
Electronic Properties of Carbon Nanotubes \\ Edited by Prof. Jose Mauricio Marulanda
}

ISBN 978-953-307-499-3

Hard cover, 680 pages

Publisher InTech

Published online 27, July, 2011

Published in print edition July, 2011

Carbon nanotubes (CNTs), discovered in 1991, have been a subject of intensive research for a wide range of applications. These one-dimensional (1D) graphene sheets rolled into a tubular form have been the target of many researchers around the world. This book concentrates on the semiconductor physics of carbon nanotubes, it brings unique insight into the phenomena encountered in the electronic structure when operating with carbon nanotubes. This book also presents to reader useful information on the fabrication and applications of these outstanding materials. The main objective of this book is to give in-depth understanding of the physics and electronic structure of carbon nanotubes. Readers of this book should have a strong background on physical electronics and semiconductor device physics. This book first discusses fabrication techniques followed by an analysis on the physical properties of carbon nanotubes, including density of states and electronic structures. Ultimately, the book pursues a significant amount of work in the industry applications of carbon nanotubes.

\title{
How to reference
}

In order to correctly reference this scholarly work, feel free to copy and paste the following:

Atsushi Suzuki and Takeo Oku (2011). Electronic Structure and Magnetic Properties of N@C60-SWCNT, Electronic Properties of Carbon Nanotubes, Prof. Jose Mauricio Marulanda (Ed.), ISBN: 978-953-307-499-3, InTech, Available from: http://www.intechopen.com/books/electronic-properties-of-carbonnanotubes/electronic-structure-and-magnetic-properties-of-n-c60-swcnt

\section{INTECH}

open science | open minds

\section{InTech Europe}

University Campus STeP Ri

Slavka Krautzeka 83/A

51000 Rijeka, Croatia

Phone: +385 (51) 770447

Fax: +385 (51) 686166

www.intechopen.com

\section{InTech China}

Unit 405, Office Block, Hotel Equatorial Shanghai

No.65, Yan An Road (West), Shanghai, 200040, China

中国上海市延安西路65号上海国际贵都大饭店办公楼 405 单元

Phone: +86-21-62489820

Fax: $+86-21-62489821$ 
(C) 2011 The Author(s). Licensee IntechOpen. This chapter is distributed under the terms of the Creative Commons Attribution-NonCommercialShareAlike-3.0 License, which permits use, distribution and reproduction for non-commercial purposes, provided the original is properly cited and derivative works building on this content are distributed under the same license. 